\title{
Two-component spike nanoparticle vaccine protects macaques from SARS-CoV-2 infection
}

\section{Graphical Abstract}

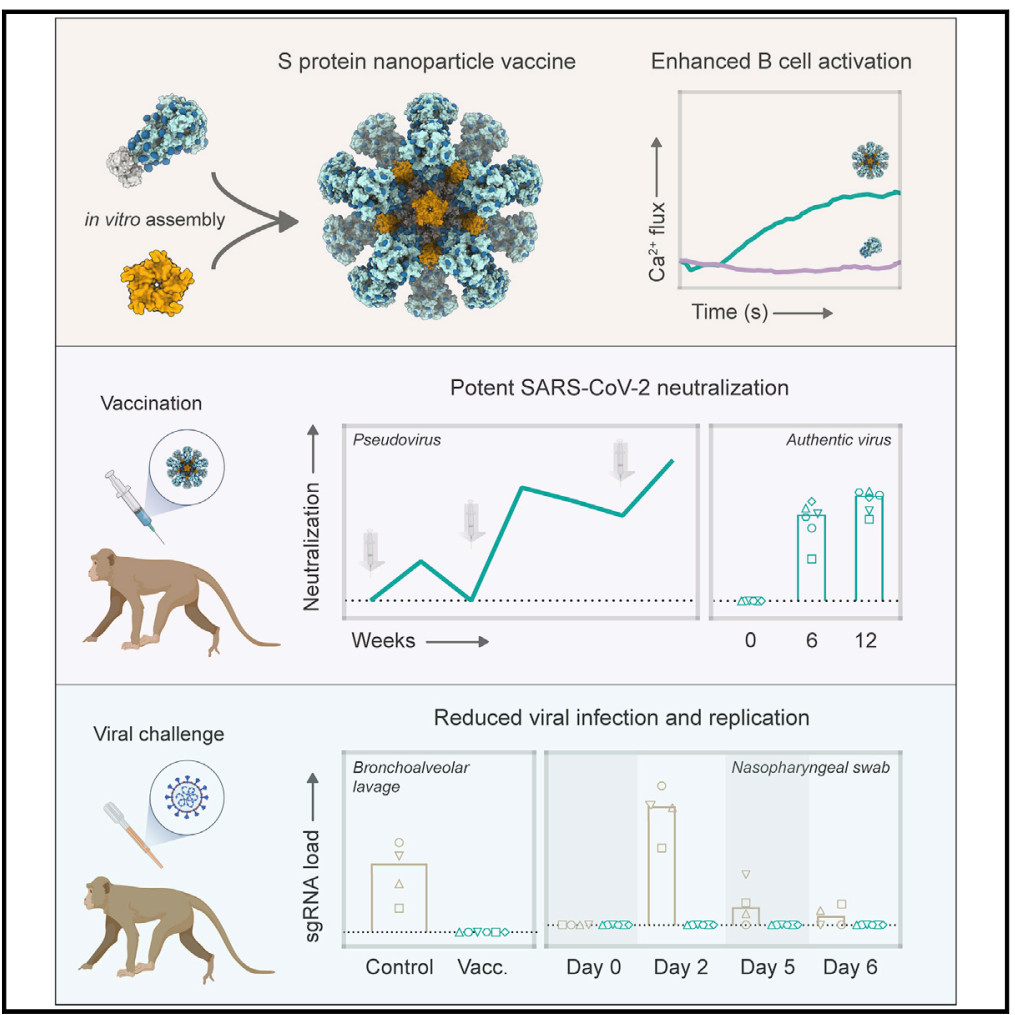

Highlights

- Two-component protein nanoparticles display multiple copies of the SARS-CoV-2 spike

- Spike protein nanoparticles enhance cognate B cell activation in vitro

- Vaccination induces potent neutralization in mice, rabbits, and cynomolgus macaques

- Vaccination protects macaques against a high-dose SARSCoV-2 challenge

\section{Authors}

Philip J.M. Brouwer, Mitch Brinkkemper, Pauline Maisonnasse, ..., Marit J. van Gils, Roger Le Grand, Rogier W. Sanders

\section{Correspondence}

roger.le-grand@cea.fr (R.L.G.), r.w.sanders@amsterdamumc.nl (R.W.S.)

\section{In Brief}

Brouwer et al. present preclinical evidence in support of a COVID-19 vaccine candidate, designed as a selfassembling two-component protein nanoparticle displaying multiple copies of the SARS-CoV-2 spike protein, which induces strong neutralizing antibody responses and protects from high-dose SARS-CoV-2 challenge. 


\section{Two-component spike nanoparticle vaccine protects macaques from SARS-CoV-2 infection}

Philip J.M. Brouwer, ${ }^{1,14}$ Mitch Brinkkemper, ${ }^{1,14}$ Pauline Maisonnasse, ${ }^{2,14}$ Nathalie Dereuddre-Bosquet, ${ }^{2}$ Marloes Grobben, ${ }^{1}$ Mathieu Claireaux, ${ }^{1}$ Marlon de Gast, ${ }^{1}$ Romain Marlin, ${ }^{2}$ Virginie Chesnais, ${ }^{3}$ Ségolène Diry, ${ }^{3}$ Joel D. Allen, ${ }^{4}$ Yasunori Watanabe, ${ }^{4,5}$ Julia M. Giezen, ${ }^{1}$ Gius Kerster, ${ }^{1}$ Hannah L. Turner, ${ }^{6}$ Karlijn van der Straten, ${ }^{1}$ Cynthia A. van der Linden, ${ }^{1}$ Yoann Aldon, ${ }^{1}$ Thibaut Naninck, ${ }^{2}$ Ilja Bontjer, ${ }^{1}$ Judith A. Burger, ${ }^{1}$ Meliawati Poniman, ${ }^{1}$ Anna Z. Mykytyn, ${ }^{7}$ Nisreen M.A. Okba, ${ }^{7}$ Edith E. Schermer, ${ }^{1}$ Marielle J. van Breemen, ${ }^{1}$ Rashmi Ravichandran, 8,9 Tom G. Caniels, ${ }^{1}$ Jelle van Schooten, ${ }^{1}$ Nidhal Kahlaoui, ${ }^{2}$ Vanessa Contreras, ${ }^{2}$ Julien Lemaître,${ }^{2}$ Catherine Chapon, ${ }^{2}$ Raphaël Ho Tsong Fang, ${ }^{2}$ Julien Villaudy, ${ }^{10}$ Kwinten Sliepen, ${ }^{1}$ Yme U. van der Velden, ${ }^{1}$ Bart L. Haagmans, ${ }^{7}$ Godelieve J. de Bree, ${ }^{13}$ Eric Ginoux, ${ }^{3}$ Andrew B. Ward, ${ }^{6}$ Max Crispin, ${ }^{4}$ Neil P. King, ${ }^{8,9}$ Sylvie van der Werf, ${ }^{11,12}$ Marit J. van Gils, ${ }^{1}$ Roger Le Grand, ${ }^{2, *}$ and Rogier W. Sanders ${ }^{1,15, *}$

${ }^{1}$ Department of Medical Microbiology, Amsterdam UMC, University of Amsterdam, Amsterdam Infection \& Immunity Institute, 1105 AZ Amsterdam, the Netherlands

${ }^{2}$ Center for Immunology of Viral, Auto-immune, Hematological and Bacterial Diseases (IMVA-HB/IDMIT), Université Paris-Saclay, INSERM, CEA, Fontenay-aux-Roses, France

${ }^{3}$ Life and Soft, 92350 Le Plessis-Robinson, France

${ }^{4}$ School of Biological Sciences, University of Southampton, Southampton SO17 1BJ, UK

5Oxford Glycobiology Institute, Department of Biochemistry, University of Oxford, Oxford OX1 3QU, UK

${ }^{6}$ Department of Integrative Structural and Computational Biology, The Scripps Research Institute, La Jolla, CA 92037, USA

${ }^{7}$ Department of Viroscience, Erasmus Medical Center, 3015 GD Rotterdam, the Netherlands

8Department of Biochemistry, University of Washington, Seattle, WA 98195, USA

Institute for Protein Design, University of Washington, Seattle, WA 98195, USA

${ }^{10} \mathrm{AIMM}$ Therapeutics BV, 1105 BA Amsterdam, the Netherlands

${ }^{11}$ Molecular Genetics of RNA Viruses, Department of Virology, Institut Pasteur, CNRS UMR 3569, Université de Paris, Paris, France

${ }^{12}$ National Reference Center for Respiratory Viruses, Institut Pasteur, Paris, France

${ }^{13}$ Department of Internal Medicine, Amsterdam UMC, University of Amsterdam, Amsterdam Institute for Infection and Immunity, 1105 AZ Amsterdam, the Netherlands

${ }^{14}$ These authors contributed equally

${ }^{15}$ Lead contact

*Correspondence: roger.le-grand@cea.fr (R.L.G.), r.w.sanders@amsterdamumc.nl (R.W.S.)

https://doi.org/10.1016/j.cell.2021.01.035

\section{SUMMARY}

The severe acute respiratory syndrome coronavirus 2 (SARS-CoV-2) pandemic is continuing to disrupt personal lives, global healthcare systems, and economies. Hence, there is an urgent need for a vaccine that prevents viral infection, transmission, and disease. Here, we present a two-component protein-based nanoparticle vaccine that displays multiple copies of the SARS-CoV-2 spike protein. Immunization studies show that this vaccine induces potent neutralizing antibody responses in mice, rabbits, and cynomolgus macaques. The vaccine-induced immunity protects macaques against a high-dose challenge, resulting in strongly reduced viral infection and replication in the upper and lower airways. These nanoparticles are a promising vaccine candidate to curtail the SARS-CoV-2 pandemic.

\section{INTRODUCTION}

Severe acute respiratory syndrome coronavirus 2 (SARS-CoV-2) has rapidly spread across the globe and infected more than 100 million individuals since late 2019 (https://covid19.who.int/). SARS-CoV-2 causes coronavirus disease 2019 (COVID-19), which manifests itself as a mild respiratory illness in most infected individuals but can lead to acute respiratory distress syndrome and death in a significant percentage of cases. As of February $1^{\text {st }}, 2021$, COVID-19 has caused over 2 million casualties and continues to place a significant burden on healthcare systems and economies worldwide. Hence, the development of a safe and effective vaccine that can prevent SARS-CoV-2 infection and transmission has rapidly become a top priority.

Recent studies suggest that SARS-CoV-2-specific neutralizing antibody (NAb) titers are an important immune correlate of protection (Addetia et al., 2020; Yu et al., 2020). This is supported by several passive immunization studies showing that administration of potent neutralizing SARS-CoV-2-specific monoclonal antibodies (mAbs) can significantly reduce lung viral loads (Cao 
et al., 2020; Rogers et al., 2020). Thus, a successful vaccine will likely need to induce a potent NAb response. The main target for NAbs on SARS-CoV-2 is the spike (S) protein. This homotrimeric glycoprotein is anchored in the viral membrane and consists of the S1 domain, which contains the receptor-binding domain (RBD) for the host cell receptor angiotensin-converting enzyme 2 (ACE2), and the S2 domain, which contains the fusion peptide. Upon binding to ACE2, the prefusion $S$ protein undergoes several structural changes that induce a shift to a postfusion state that enables merging of the viral envelope and host cell membrane (Shang et al., 2020). As most NAb epitopes are presented on the prefusion conformation, vaccine candidates should include the prefusion $\mathrm{S}$ protein, which, as for other class I viral fusion proteins (Krarup et al., 2015; Sanders et al., 2002), can be stabilized by appropriately positioned proline substitutions (Pallesen et al., 2017; Walls et al., 2020a; Wrapp et al., 2020).

More than 200 candidate vaccines are currently under preclinical or clinical evaluation, and several have been licensed (https:// www.who.int/publications/m/item/draft-landscape-of-covid-19candidate-vaccines). Recombinant subunit vaccines provide a welcome alternative to the inactivated, viral-vector- and RNAbased vaccines that are currently in phase 3 clinical trials or in use, as they have a track record of safety and efficacy. In addition, recombinantly expressed $S$ proteins represent an efficient antigen to induce potent NAb responses, as recently reported in non-human primate studies (Guebre-Xabier et al., 2020; Liang et al., 2020; Tian et al., 2021).

A well-established strategy to generate strong humoral immune responses against soluble antigens is multivalent antigen display (Bachmann and Jennings, 2010; Moyer et al., 2016). Nanoparticles presenting a high density of antigen on a repetitive array facilitate numerous immunological processes such as $B$ cell activation, lymph node trafficking, and retention on follicular dendritic cells (Kelly et al., 2019; Tokatlian et al., 2019). Among the several nanoparticle designs that are currently being employed to present viral glycoproteins, selfassembling protein nanoparticle systems represent promising platforms, as they allow for efficient and scalable nanoparticle assembly (López-Sagaseta et al., 2015). Homomeric protein complexes such as the 24-subunit ferritin and 60-subunit mi3 nanoparticles self-assemble intracellularly and have been used to display immunogens such as influenza hemagglutinin (HA), HIV-1 Env, malaria cysteine-rich protective antigen (CyRPA), and also SARS-CoV-2 S protein and RBD (Bruun et al., 2018; He et al., 2020; Kanekiyo et al., 2013; Ma et al., 2020; Powell et al., 2021; Sliepen et al., 2015; Walls et al., 2020b). Recently, two-component 120-subunit icosahedral nanoparticles, such as the $153-50$ and dn5 designs, have been developed that self-assemble in vitro, allowing for controlled nanoparticle formation. We and others have been using these nanoparticles to multivalently present trimeric type 1 viral fusion proteins of HIV-1, respiratory syncytial virus (RSV), and influenza (Boyoglu-Barnum et al., 2020; Brouwer et al., 2019; Marcandalli et al., 2019). Presentation of these immunogens on two-component protein nanoparticles significantly improved NAb titers, which supports pursuing this platform for the generation of nanoparticle immunogens displaying prefusion SARS-CoV-2 S proteins.
Here, we describe the generation and characterization of twocomponent protein nanoparticles displaying stabilized prefusion SARS-CoV-2 S proteins. Immunization studies in mice, rabbits, and macaques demonstrated that these nanoparticles induce robust humoral responses. Vaccinated macaques challenged with a high dose of SARS-CoV-2 virus had strongly reduced viral loads in both the upper and lower respiratory tracts and developed fewer lung lesions when compared to unvaccinated animals.

\section{RESULTS}

SARS-CoV-2 S proteins can be displayed on twocomponent 153-50 nanoparticles

The computationally designed 153-50 nanoparticle (I53-50NP) constitutes 20 trimeric (I53-50A or variants thereof) and 12 pentameric (153-50B.4PT1) subunits that self-assemble to form monodisperse icosahedral particles with a diameter of $\sim 30 \mathrm{~nm}$ (Bale et al., 2016). To generate 153-50NPs presenting SARSCoV-2 S proteins, we genetically fused the $C$ terminus of the previously described stabilized prefusion $\mathrm{S}$ protein to the $\mathrm{N}$ terminus of the 153-50A variant, 153-50A.1NT1, using a glycine-serine linker (Figure 1A; Brouwer et al., 2020). The fusion protein was purified from transfected human embryonic kidney (HEK) 293F cell supernatant using nickel-nitrilotriacetic acid (Ni-NTA) purification followed by size exclusion chromatography (SEC). Collection of the appropriate SEC fractions yielded $\sim 2 \mathrm{mg} / \mathrm{L}$ trimeric SARS-CoV-2 S-I53-50A.1NT1 fusion protein (Figure 1B). To initiate assembly of nanoparticles presenting SARS-CoV-2 S proteins (SARS-CoV-2 S-153-50NPs), the pooled trimer fractions were incubated overnight at $4^{\circ} \mathrm{C}$ with $153-50 \mathrm{~B} .4 \mathrm{PT} 1$ in an equimolar ratio. The nanoparticle preparation was further purified using an additional SEC step to remove unassembled components. Negative-stain electron microscopy (nsEM) of the pooled higher-molecular-weight fractions revealed a considerable portion of monodisperse and well-ordered icosahedral nanoparticles (Figure 1C). Biolayer interferometry (BLI)-based binding experiments with a panel of SARS-CoV-2 S-protein-specific monoclonal NAbs, previously isolated from recovered COVID-19 patients (Brouwer et al., 2020), showed strong binding of RBD-specific COVA1-18, COVA2-02, COVA2-15, and COVA2-39 and N-terminal domain (NTD)-specific COVA1-22 to trimeric SARS-CoV-2 S-153-50A.1NT1 and SARS-CoV-2 S-153$50 N P$ (Figure 1D). This suggests that presentation of SARSCoV-2 S protein on 153-50NPs did not compromise the structure of these $S$ protein epitopes. Altogether, SEC, nsEM, and BLI confirmed the successful generation of nanoparticles presenting multiple copies of the SARS-CoV-2 S protein.

As approximately one-third of the mass of the SARS-CoV-2 S protein consists of $\mathrm{N}$-linked glycans, we sought to identify the site-specific glycosylation of S protein presented on 153-50NPs using liquid chromatography-mass spectrometry (LC-MS). All sites presented high levels of occupancy, with only N1074 displaying $15 \%$ of sites lacking an N-linked glycan (Figure S1A). The compositions of glycans present at the $19 \mathrm{~N}$-linked glycan sites on the $S$ protein were determined and revealed a diverse range of structures (Figure S1B). Underprocessed oligomannose-type glycans were observed at sites N61, N234, N717, 
Cell Article
A

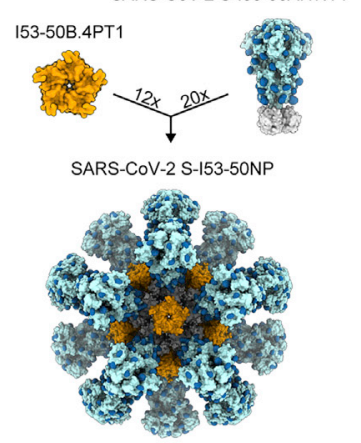

C SARS-COV-2 S-153-50NP

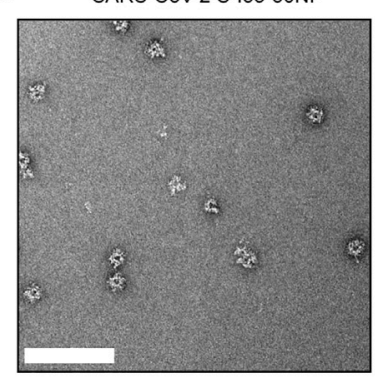

B $\bullet$ SARS-CoV-2 S-I53-50A.1NT1 •SARS-CoV-2 S-I53-50NP

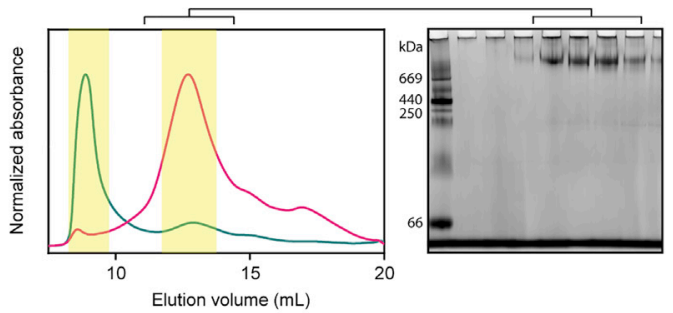

D
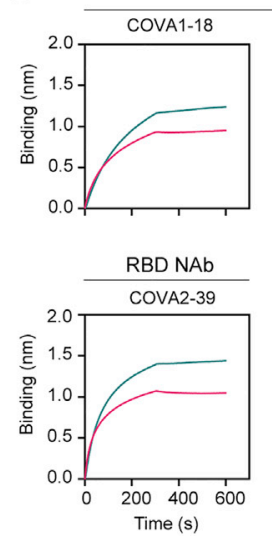

RBD NAb

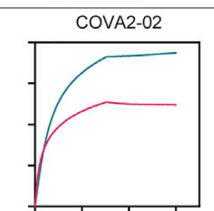

NTD NAb COVA1-22

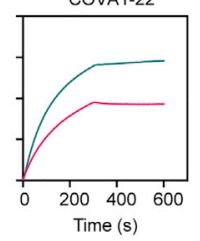
COVA2-15

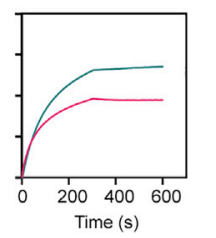

Figure 1. Biophysical and antigenic characterization of SARS-CoV-2 S-I53-50NPs

(A) Schematic representation of 20 copies of SARS-CoV-2 S-I53-50A.1NT1 (SARS-CoV-2 S in light blue, glycans in dark blue, and I53-50A.1NT1 in white) and 12 copies of I53-50B.4PT1 assembling into SARS-CoV-2 S-I53-50NP.

(B) Size exclusion chromatograms of SARS-CoV-2 S-153-50A.1NT1 (magenta) and SARS-CoV-2 S153-50NP (green) run over a Superose 6 increase $10 / 300 \mathrm{GL}$ column. The yellow columns specify the SEC fractions that were collected, pooled, and used. Blue native gel of pooled SARS-CoV-2 S153-50A.1NT1 SEC fractions.

(C) Negative-stain electron microscopy (nsEM) analysis of assembled SARS-CoV-2 S-153-50NPs. The white bar represents $200 \mathrm{~nm}$.

(D) BLI sensorgrams showing the binding of multiple SARS-CoV-2 NAbs to SARS-CoV-2 S-I5350A.1NT1 (magenta) and SARS-CoV-2 S-I5350NP (green).

See also Figure S1.

(Brouwer et al., 2020). In control experiments, 153-50NPs displaying soluble HIV-1 envelope glycoproteins (BG505 SOSIP) did not activate any of the $B$ cell lines. We conclude that SARS-

and N801 and to a lesser extent at N1098. The average oligomannose-type glycan content across all sites was $11 \%$. Processed complex-type glycans were observed at all sites and were highly fucosylated $(73 \%)$ but mostly lacked sialylation (8\%) (Figures S1A and S1B). The glycoforms present on SARS-CoV-2 S-I53-50NPs are more processed compared to other recombinant $S$ protein immunogens (Watanabe et al., 2020) but are reminiscent of the composition on S proteins presented on virions (Yao et al., 2020).

SARS-CoV-2 S-I53-50NPs enhance activation of SARSCoV-2 S-protein-specific B cells in vitro

Multivalent display of antigens can enhance cognate B cell activation over soluble antigen (Antanasijevic et al., 2020; Brouwer et al., 2019; Veneziano et al., 2020). To assess if the same would apply for SARS-CoV-2 S-153-50NPs, we generated $B$ cells that expressed $B$ cell receptors (BCRs) for previously described RBD-targeting monoclonal NAbs and measured their activation by monitoring $\mathrm{Ca}^{2+}$ influx in vitro (Brouwer et al., 2020). Soluble trimers only weakly activated COVA1-18-expressing $B$ cells at the highest concentration used (5 $\mu \mathrm{g} / \mathrm{mL}$ SARS-CoV-2 S-I53-50A.1NT1), while an equimolar amount of SARS-CoV-2 S presented on 153-50NPS efficiently activated the same B cells (Figure 2). COVA2-15expressing $B$ cells were activated by soluble SARS-CoV-2 S-153-50A.1NT1 trimers but markedly more efficiently so by SARS-CoV-2 S-153-50NP. The more efficient activation of COVA2-15-expressing $B$ cells compared to those expressing COVA1-18 may be explained by the fact that COVA2-15 can interact with the RBD in both the up and down state, which may result in higher-avidity interactions
CoV-2 S-153-50NPs improve the activation of SARS-CoV-2specific $B$ cells compared to soluble trimers.

\section{SARS-CoV-2 S-I53-50NP vaccination induces robust $\mathrm{NAb}$ responses in small-animal models} We assessed the immunogenicity of SARS-CoV-2 S-153-50NPs in two small-animal models. Eight BALB/c mice were immunized with $10 \mu \mathrm{g}$ SARS-CoV-2 S presented on I53-50NPs, adjuvanted in polyinosinic-polycytidylic acid (poly(l:C)). In addition, five New Zealand white rabbits were immunized with $30 \mu \mathrm{g}$ SARS-CoV-2 S presented on I53-50NPs, adjuvanted in squalene emulsion. Mice and rabbits received three subcutaneous and intramuscular immunizations, respectively, at weeks 0,4 , and 12 (Figure 3A). The adjuvants were chosen based on our previous positive experiences with them in the respective animal models.

Two weeks after the first immunization, mice and rabbits induced detectable SARS-CoV-2 S-protein-specific immunoglobulin G ( $\operatorname{lgG}$ ) titers, as determined by an enzyme-linked immunosorbent assay (ELISA), with a median endpoint binding titer of 2,920 and 5,105 respectively. In mice, median endpoint titers were further boosted after the second immunization to 57,943 at week 6 and slightly decreased after the third immunization to 47,643 at week 14 (Figure 3B). In rabbits, median endpoint titers were boosted to 544,503 at week 6 and 594,292 at week 14 (Figure 3C). Neutralization of SARS-CoV-2 pseudovirus was already detectable in the majority of mice and rabbit sera 2 weeks after the first immunization. NAb titers, which are represented by the inhibitory dilutions at which $50 \%$ neutralization is attained ( $\mathrm{ID}_{50}$ values), increased to a median of 16,792 at week 6 and 49,039 at week 14 in mice (Figure 3D; Table S1). In rabbits, NAb titers were 

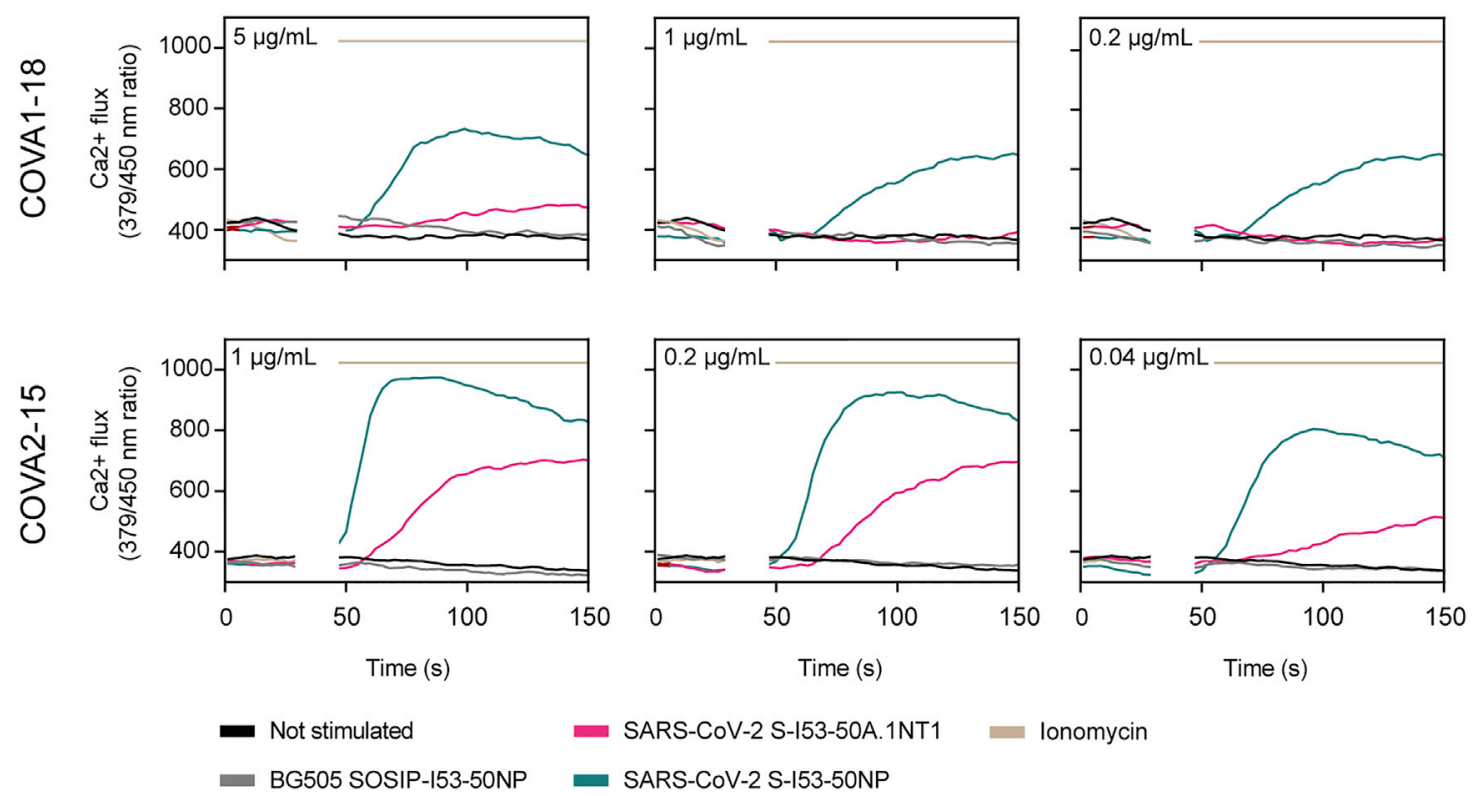

Figure 2. In vitro B cell activation by SARS-CoV-2 S-I53-50A.1NT1 and SARS-CoV-2 S-I53-50NPs

B cells expressing the SARS-CoV-2 S-protein-specific NAbs COVA1-18 (top) or COVA2-15 (bottom) as BCRs were incubated with either SARS-CoV-2 S-I5350A.1NT1 (magenta), SARS-CoV-2 S-153-50NP (green), ionomycin (beige), or BG505 I53-50NP (gray) or not stimulated (black). The experiments were performed with 5, 1, 0.2, or $0.04 \mu \mathrm{g} / \mathrm{mL}$ SARS-CoV-2 S-I53-50A.1NT1, as indicated in the top left corner of each graph, or the equimolar amount of SARS-CoV-2 S or BG505 SOSIP on I53-50NPs. Ionomycin was used at $1 \mathrm{mg} / \mathrm{mL}$ as a positive control.

boosted to a median ID $\mathrm{D}_{50}$ of 68,298 and 135,128 at weeks 6 and 14 , respectively (Figure 3E; Table S1). Neutralization titers of authentic SARS-CoV-2 virus at week 14 reached a median $I_{50}$ of 4,065 and 15,110 in mice and rabbits, respectively (Figures 3D and 3E; Table S1). Collectively, we showed that SARS-CoV-2 S-I53-50NPs were able to induce robust binding and NAb responses in both mice and rabbits after two and three immunizations.

SARS-CoV-2 S-I53-50NP vaccination induces potent humoral responses in cynomolgus macaques

The high binding and neutralization titers in mice and rabbits supported subsequent assessment of the immunogenicity of SARS-CoV-2 S-I53-50NPs in cynomolgus macaques, an animal model that is immunologically closer to humans. Six cynomolgus macaques were immunized with $50 \mu \mathrm{g}$ SARS-CoV-2 S-I5350NPs formulated in monophospholipid A (MPLA) liposomes by the intramuscular route at weeks 0,4 , and 10 (Figure 4A). The MPLA liposome adjuvant was chosen because it is used in several human clinical trials (e.g., NCT03816137, NCT03961438, and NCT04046978) and is a component of the widely used AS01 adjuvant, which was safe and effective in several phase 3 clinical trials (Lal et al., 2018; Agnandji et al., 2012).

To analyze the frequency of S protein and RBD-specific IgGpositive $B$ cells in macaques after vaccination, peripheral blood mononuclear cells at week 12 were gated on the expression of CD20 and IgG and stained with fluorescently labeled prefusion SARS-CoV-2 S protein or RBD (Figure 4B). We observed a clear expansion of SARS-CoV-2 S-protein-specific $B$ cells by vaccination, which constituted on average $\sim 1 \%$ of total B cells (Figure 4 C). Within the population of IgG-positive SARS-CoV-2 S- protein-specific B cells, on average, $\sim 30 \%$ bound to the RBD (Figure $4 \mathrm{C}$ ). Within the CD27 ${ }^{+} \mathrm{B}$ cell population (marker for memory $\mathrm{B}$ cells), on average, $0.77 \%$ were SARS-CoV-2 S protein specific, of which, again, $\sim 30 \%$ were specific for the RBD (Figure S2). In addition to B cells, SARS-CoV-2 S-protein-specific $T$ cells were also markedly expanded, as determined by an enzyme-linked immune absorbent spot assay (ELISpot) (Figure 4D). Furthermore, we studied circulating $T$ follicular helper cells (cTfh cells), the circulating counterpart of germinal center Tfh cells (Heit et al., 2017; Vella et al., 2019). We observed pronounced expansion of S-protein-specific cTfh cells $\left(\mathrm{CD}^{+} 9^{+}\right.$ $\mathrm{CD}_{154^{+}} \mathrm{CXCR}^{+}$) within the CD4 ${ }^{+} \mathrm{T}$ cell subset, as determined by the activation-induced marker (AIM) assay (Figures $4 \mathrm{E}$ and S3A-S3C). Within CD4 ${ }^{-} \mathrm{T}$ cells (CD8 ${ }^{+} \mathrm{T}$ cells by inference), a trend toward higher expansion of cells was observed in the vaccinated macaques (Figure S3D)

Sera of the immunized macaques exhibited SARS-CoV-2 Sprotein-specific binding IgG responses with median endpoint titers of $211,1,601$ and 2,190, at weeks 2,6 , and 12, respectively (Figure 5A). To compare binding titers to SARS-CoV-2 S protein and RBD between sera from vaccinated macaques and those from convalescent humans from the COVID-19 Specific Antibodies (COSCA) cohort (sampled $\sim 4$ weeks after the onset of symptoms) (Brouwer et al., 2020), a different ELISA protocol was used. Specifically, binding responses were compared to a standard curve of species-specific polyclonal lgG so that a semiquantitative measure of specific IgG concentrations could be obtained. Week 6 and 12 sera elicited markedly higher IgG binding titers to SARS-CoV-2 S protein than serum from convalescent humans (Figure 5B). This was also the case for RBD-specific binding titers (Figure 5C). 
A

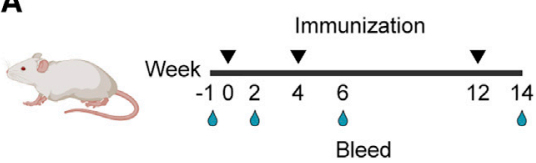

B

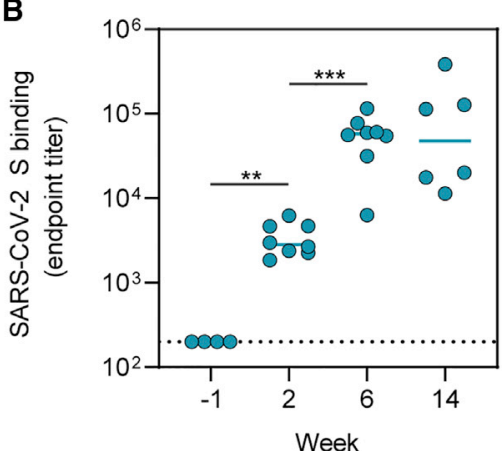

D

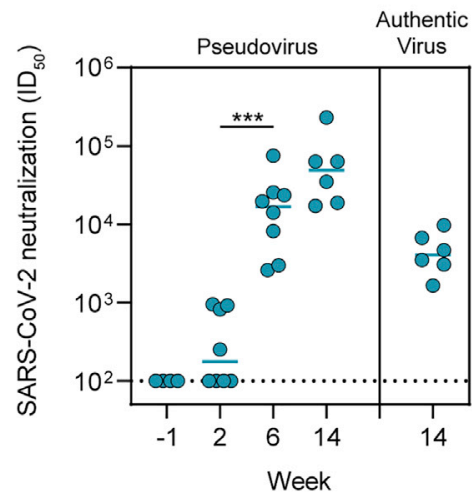

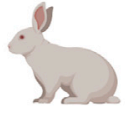

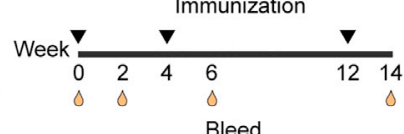

Bleed

C

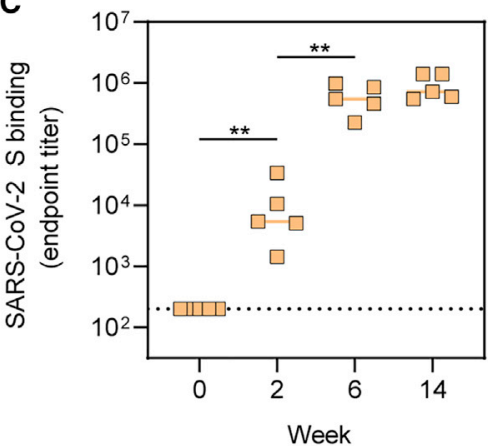

E

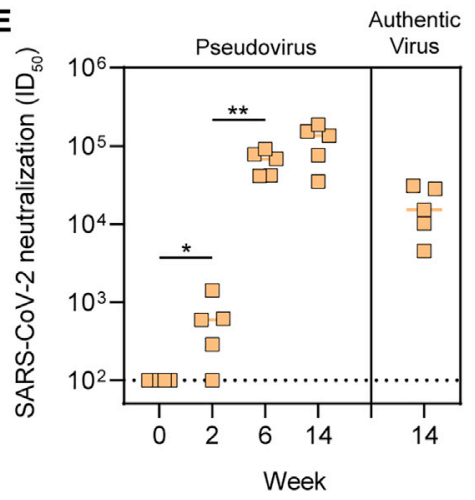

Figure 3. Immunogenicity of SARS-CoV-2 S-153-50NPs in mice and rabbits

(A) Study schedule in mice (left) and rabbits (right). Black triangles indicate the time points of immunization and drops indicate the bleeds.

(B) ELISA endpoint titers for SARS-CoV-2 S-protein-specific lgG in mice.

(C) ELISA endpoint titers for SARS-CoV-2 S-protein-specific IgG in rabbits.

(D) SARS-CoV-2 pseudovirus and authentic virus neutralization titers in mice.

(E) SARS-CoV-2 pseudovirus and authentic virus neutralization in rabbits.

In (B) and (C), due to limited volumes of sera at week -1 , random pairs of mice sera were pooled. At week 6, two animals were sacrificed. In (B)-(E), the median titers are indicated by a bar. Titers between boosts were compared using the MannWhitney U test $\left({ }^{\star} p<0.05 ;{ }^{* \star} p<0.01 ;{ }^{* \star *} p<0.001\right)$.

Serum neutralization titers in the vaccinated macaques were overall robust. Two weeks after the first immunization, macaques induced pseudovirus neutralization with a median $I D_{50}$ of 475 . The second immunization increased the neutralization titers to a median $\mathrm{ID}_{50}$ of 8,865 , which then declined only modestly up to the third immunization. NAb titers were further increased to a median $I D_{50}$ of 26,361 at week 12 (Figure 5E; Table S2). At week 6 , the neutralization titers were similar to those in sera from convalescent humans, but neutralization titers

Using a custom Luminex-bead-based serological assay, we analyzed the induction of several Ig isotypes in serum, nasopharyngeal swab, and saliva samples of the vaccinated macaques over time. S-protein-specific IgG levels in serum showed a similar course as observed by ELISA (Figures 5D and S4A). This was also the case for IgA, albeit with a more rapid onset and waning after vaccination. As expected, IgM levels peaked after the first immunization and gradually waned thereafter, presumably as a result of Ig class switching (Figures 5D and S4A). We also observed an increase in S-specific IgG and IgA levels in nasopharyngeal swabs and saliva after consecutive immunizations. This was particularly clear for IgG in nasopharyngeal swabs (Figures 5D and S4B). The results in saliva samples were more variable (Figures 5D and S4C). Thus, in addition to a systemic antibody response, SARS-CoV-2 S-I53-50NPs induced detectable mucosal $\lg A$ and $\lg G$ responses, a relevant finding considering that the respiratory mucosa is the first port of entry for SARSCoV-2 (Sungnak et al., 2020). Finally, we analyzed the ability of SARS-CoV-2 S-protein-specific serum antibodies to bind to immune proteins that play a role in $\mathrm{Fc}$-mediated effector functions. The levels of Fc $\gamma$ RIla, Fc $\gamma$ RIIla, and C1q binding tracked with IgG levels, suggesting that the induced IgGs can perform effector functions such as antibody-dependent cellular-cytotoxicity, phagocytosis, and complement activation (Figure S4D). at week 12 were significantly higher in vaccinated macaques than convalescent humans (median $I_{50}$ of 26,361 versus 8,226, $p=0.0012$ ) (Figure 5F). Neutralization of authentic SARS-CoV-2 was lower than that of pseudovirus but remained potent (median $\mathrm{ID}_{50}$ of 1,501 and 3,942 at weeks 6 and 12, respectively) (Figure 5G; Table $\mathrm{S} 2$ ).

\section{SARS-CoV-2 S-I53-50NP vaccination protects} cynomolgus macaques from high-dose SARS-CoV-2 challenge

To assess the protective potential of SARS-CoV-2 S-I53-50NPS, vaccinated macaques and contemporaneous control macaques $(n=4)$ were infected with a total dose of $1 \times 10^{6}$ plaque-forming units (PFUs) of a primary SARS-CoV-2 isolate (BetaCoV/France/ IDF/0372/2020; passaged twice in VeroE6 cells) by combined intranasal $(0.25 \mathrm{~mL}$ in each nostril) and intratracheal $(4.5 \mathrm{~mL}$ in the trachea) routes at week 12, 2 weeks after the final immunization. This represents a high-dose challenge in comparison with other studies, where 10- to 100-fold lower doses were used (van Doremalen et al., 2020; Feng et al., 2020; Guebre-Xabier et al., 2020; Mercado et al., 2020; Patel et al., 2020; Yu et al., 2020). Control animals had high viral load levels in nasopharyngeal and tracheal samples (swabs), as assessed by qRT-PCR for viral RNA, as early as 1 day post-exposure (dpe). In tracheal 
A
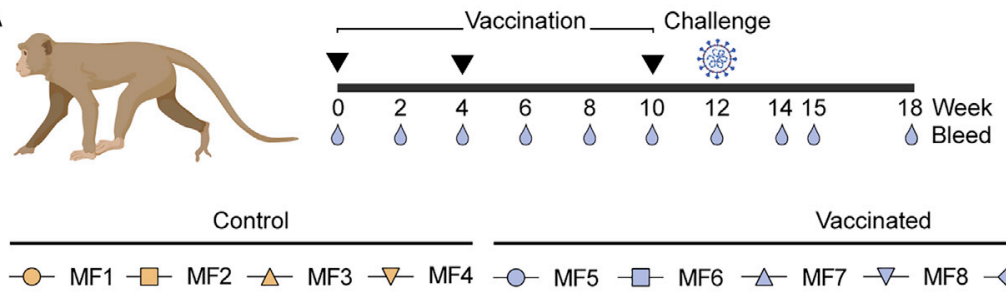

$\frac{\text { Vaccinated }}{- \text { MF5 } \square-\text { MF6 } \downarrow \text { MF7 } \neg-\text { MF8 } \diamond-\text { MF9 } \multimap \text { MF10 }}$

B
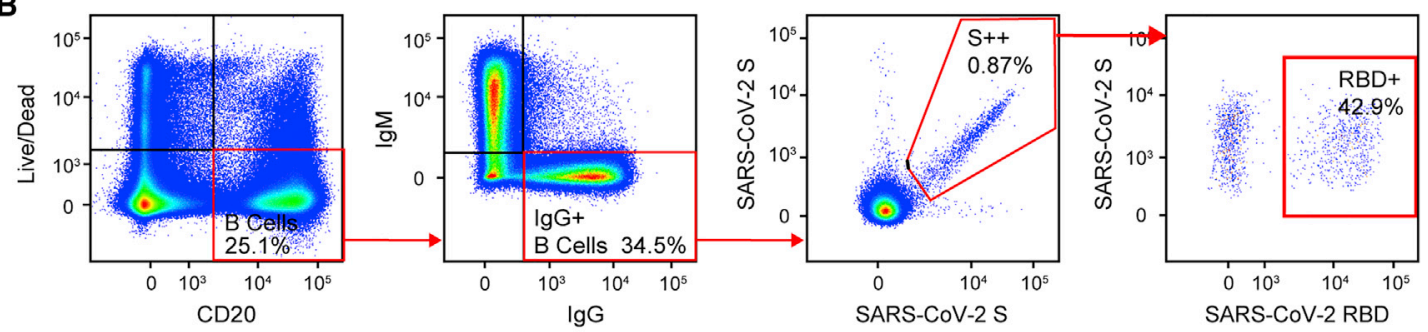

C
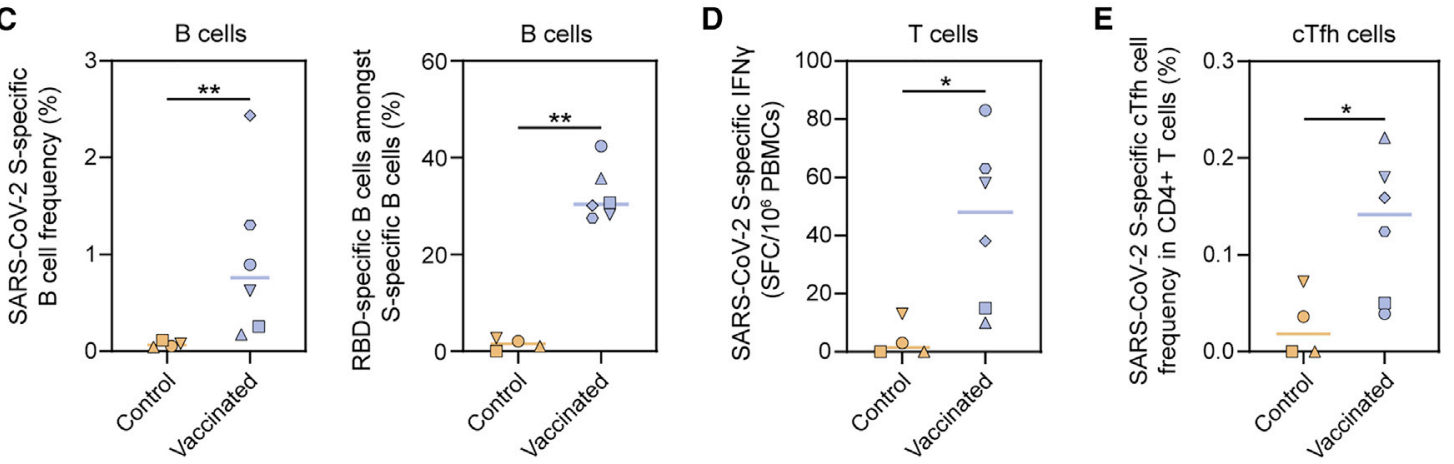

Figure 4. SARS-CoV-2 S-protein-specific B and T cell responses induced by SARS-CoV-2 S-I53-50NPs in cynomolgus macaques (A) Vaccination, challenge, and sampling schedule in cynomolgus macaques. Black triangles indicate the time points of vaccination and drops mark the bleeds. The symbols identifying individual macaques are used consistently throughout Figures 4, 5, and 6.

(B) Representative gating strategy, depicting the analysis of SARS-CoV-2 S protein and RBD-specific $\operatorname{lgG}^{+} \mathrm{B}$ cells, shown for one vaccinated macaque. The lymphocyte population was selected, and doublets were excluded (not shown). Gating strategy from the left to the right: viable B cells (live/dead ${ }^{-} \mathrm{CD}^{2} \mathrm{O}^{+}$), lgG ${ }^{+} \mathrm{B}$ cells $\left(\mathrm{IgM}^{-} \operatorname{lgG}{ }^{+}\right.$), SARS-CoV-2 S protein (double probe staining), and RBD-specific (single probe staining) $\operatorname{lgG}{ }^{+} B$ cells.

(C) SARS-CoV-2 S-protein-specific B cell frequencies within the lgG ${ }^{+}$population in control and vaccinated macaques (left). Percentages of SARS-CoV-2 RBDspecific $B$ cells within the population of SARS-CoV-2 S-protein-specific $\operatorname{lgG}^{+} B$ cells (right).

(D) Number of interferon- $\gamma$ (IFN $\gamma$ )-secreting cells after ex vivo stimulation with SARS-CoV-2 S protein as analyzed by ELISpot and plotted as spot-forming cells (SFCs) per $1.0 \times 10^{6}$ peripheral blood mononuclear cells (PBMCs).

(E) Frequency of SARS-CoV-2 S-protein-specific Tfh cells $\left(\mathrm{CD} 69^{+} \mathrm{CD} 154^{+} \mathrm{CXCR} 5^{+}\right)$in the total $\mathrm{CD} 4^{+} \mathrm{T}$ cell population. PBMCs were stimulated overnight with SARS-CoV-2 S protein and Th activation was assessed the next day by analyzing CD69 and CD154 expression by flow cytometry. The gating strategy used to identify this population is shown in Figure S3.

In (C)-(E) medians are indicated by a bar. Groups were compared using the Mann-Whitney $U$ test $\left({ }^{*} \mathrm{p}<0.05 ;{ }^{* *} \mathrm{p}<0.01\right)$.

See also Figures S2 and S3.

samples, viral loads peaked between 1 and 3 dpe, with a median value of $6.9 \log _{10}$ copies $/ \mathrm{mL}$. Subsequently, viral loads progressively decreased, and all animals had undetectable viral loads by 14 dpe (Figures 6A and S5). Similar profiles were observed in nasopharyngeal swabs, although viral loads remained detectable in some macaques at $14 \mathrm{dpe}$ (Figures $6 \mathrm{~A}$ and S5). Viral loads were markedly lower in rectal samples but stayed above the limit of detection during the course of sampling for two out of four control macaques (Figure S5). Viral subgenomic RNA (sgRNA), which is believed to reflect viral replication, peaked at 2 dpe in tracheal and nasopharyngeal swabs (median viral sgRNA load 4.8 and $6.1 \log _{10}$,respectively) and was still detectable (>2.5 $\log _{10}$ copies/mL of viral sgRNA) at 5 and 6 dpe in the nasopharynx for three and two animals, respectively (Figure 6B).

In vaccinated macaques, median peak viral loads were $300-$ fold lower in tracheal samples $\left(6.8 \log _{10}\right.$ versus $4.3 \log _{10} ; p=$ 0.0095 ) and 500 -fold lower in nasopharyngeal samples compared to unvaccinated controls $\left(7.9 \log _{10}\right.$ versus $5.2 \log _{10}$; $p=0.0095)$. With the exception of MF7, all vaccinated animals had undetectable loads at $6 \mathrm{dpe}$ in tracheal and nasopharyngeal 
A

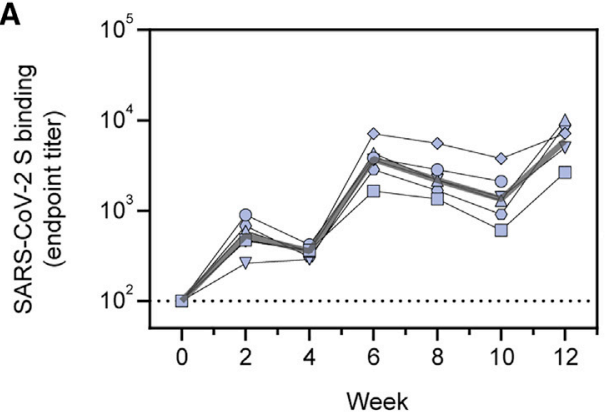

B

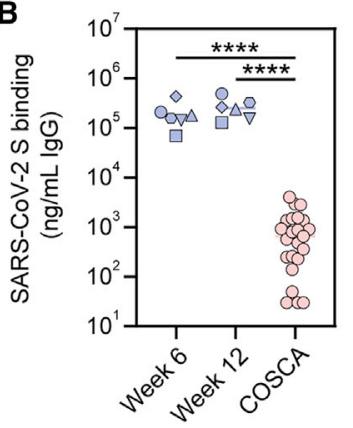

C

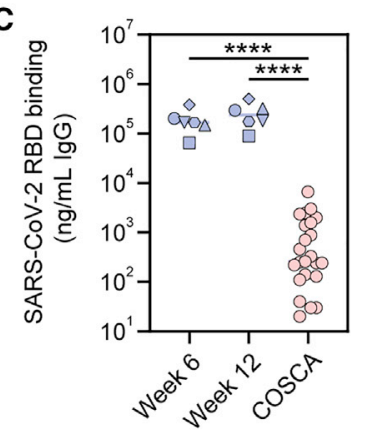

D
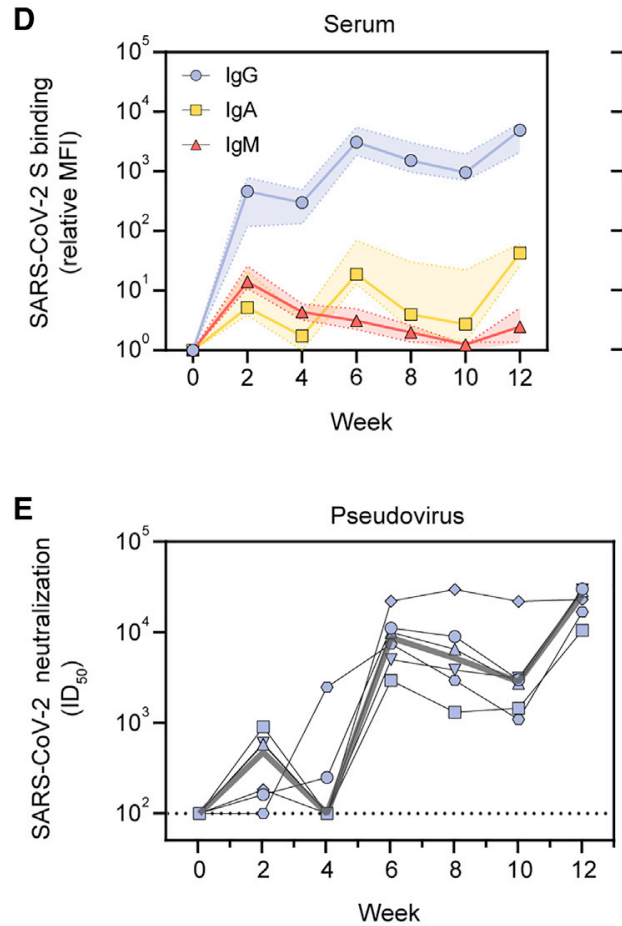

Nasopharyngeal swab

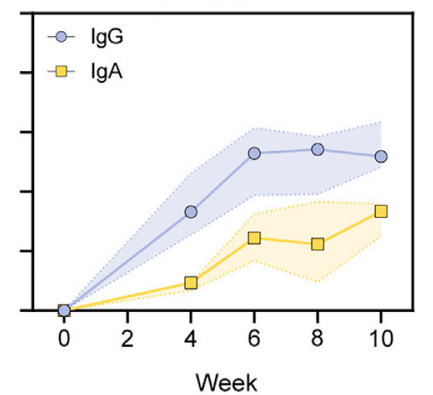

$\mathbf{F}$

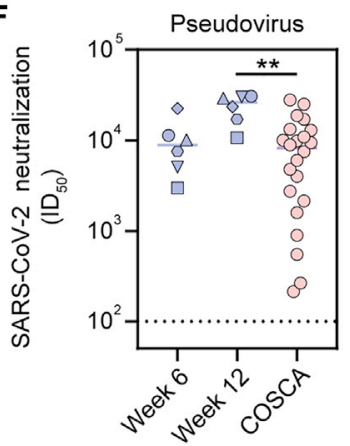

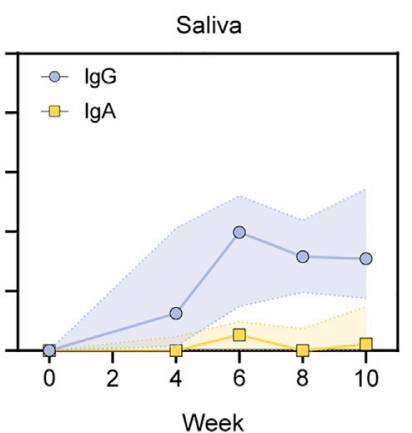

G

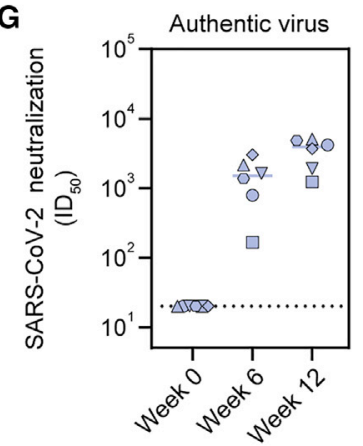

Figure 5. Serological responses induced by SARS-CoV-2 S-I53-50NPs in cynomolgus macaques (A) ELISA endpoint titers for SARS-CoV-2 S-protein-specific IgG. The gray line represents the median titers over time.

(B) SARS-CoV-2 S-protein-specific binding titers at weeks 6 and 12 in macaques compared to those in convalescent humans from the COSCA cohort. Patient samples were taken 4 weeks after onset of symptoms.

(C) SARS-CoV-2 RBD-specific binding titers at weeks 6 and 12 in macaques compared to those in convalescent humans from the COSCA cohort.

(D) Relative mean fluorescence intensity (MFI) of IgG, IgA, and IgM binding to SARS-CoV-2 S protein measured with a Luminex-based serology assay in serum samples, nasopharyngeal swabs, and saliva samples. Shown are medians with the shaded areas indicating the interquartile ranges.

(E) SARS-CoV-2 pseudovirus neutralization titers. The gray line represents median titers.

(F) SARS-CoV-2 pseudovirus neutralization titers at weeks 6 and 12 in macaques compared to those in convalescent humans from the COSCA cohort.

(G) SARS-CoV-2 authentic virus neutralization titers at weeks 6 and 12. The bars show the median titers.

In (B), (C), and (F), groups were compared using the Mann-Whitney $U$ test $\left({ }^{* \star} \mathrm{p}<0.01 ;{ }^{* \star \star *} \mathrm{p}<0.0001\right)$. The bars indicate median titers. The dotted lines indicate the lowest serum dilution.

See also Figure S4.

swabs (Figures 6A and S5). In addition to the upper airways, SARS-CoV-2 S-153-50NP vaccination significantly decreased viral loads in the lower airways, as demonstrated by a 275 -fold lower median viral load in the bronchoalveolar lavage (BAL) (6.5 $\log _{10}$ versus $\left.4.1 \log _{10} ; p=0.0095\right)$. Viral replication was also significantly reduced in vaccinated animals. Only two out of six vaccinated animals (MF5 and MF6) showed detectable
sgRNA in the trachea at 2 dpe, and median viral loads were 160 -fold lower than in control animals $\left(4.7 \log _{10}\right.$ versus 2.5 $\left.\log _{10} ; p=0.0095\right)$. In the nasopharynx, sgRNA remained below the limit of detection at any of the time points. At 2 dpe, median sgRNA loads in the vaccinated animals were 5,400-fold lower than in controls $\left(6.2 \log _{10}\right.$ versus $\left.2.5 \log _{10} ; p=0.0048\right)$ (Figure $6 \mathrm{~B}$ ). In BAL samples, we observed a 120-fold reduction of 
A
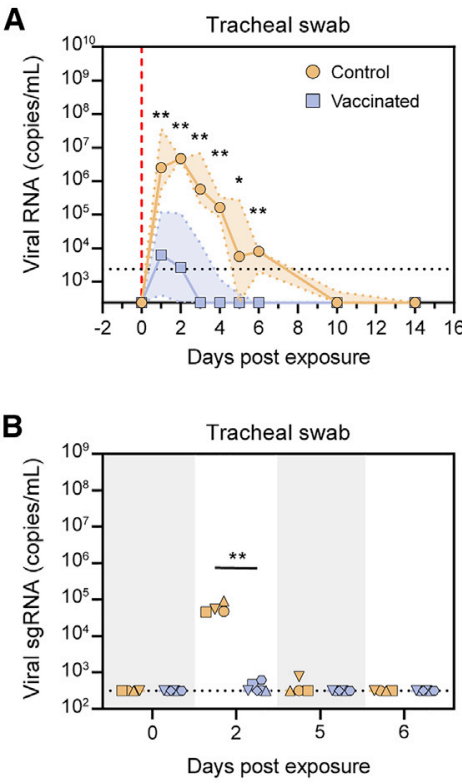
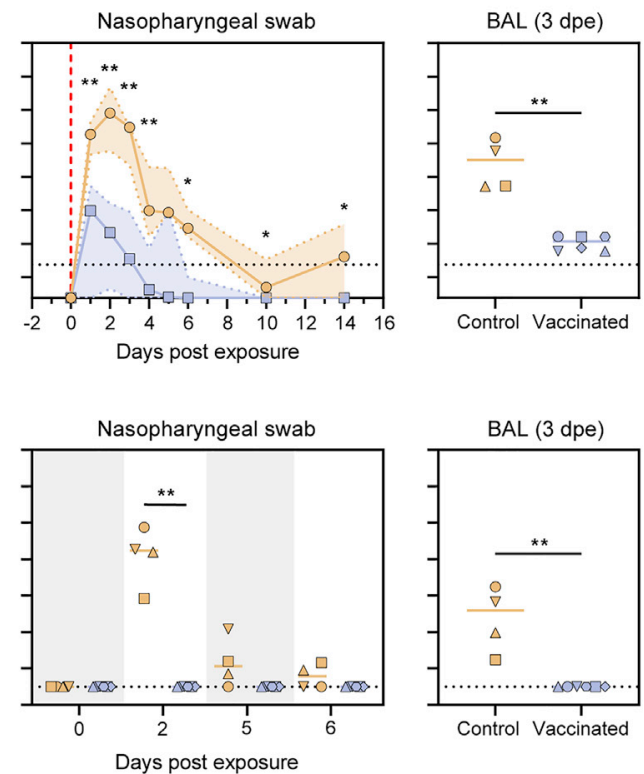

C
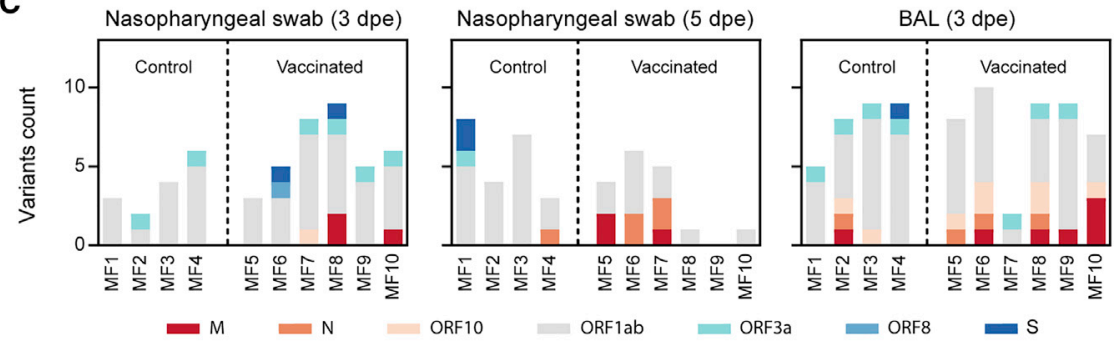

D
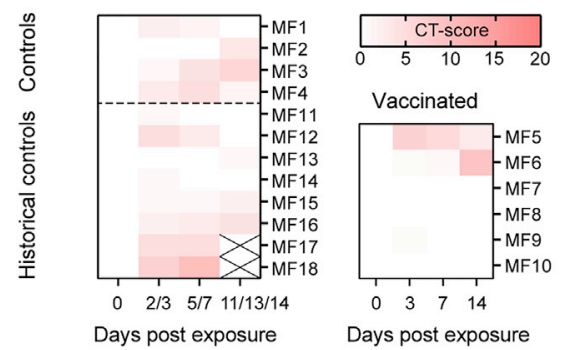

E

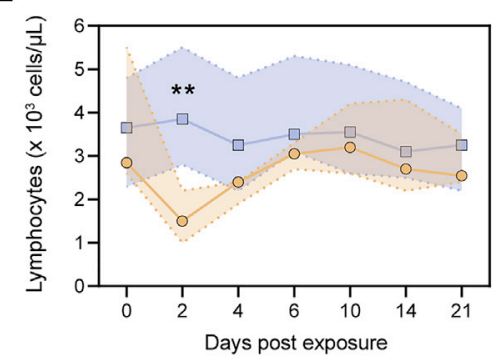

Figure 6. Protective efficacy of SARS-CoV-2 S-I53-50NPs in cynomolgus macaques (A) Median RNA viral loads in tracheal swabs (left) and nasopharyngeal swabs (middle) of control and vaccinated macaques after challenge. The shaded area indicates the range. Viral loads in control and vaccinated macaques after challenge in BAL are shown (right). Bars indicate median viral loads. Vertical red dotted lines indicate the day of challenge. Horizontal dotted lines indicate the limit of quantification.

(B) sgRNA viral loads in tracheal swabs (left), nasopharyngeal swabs (middle), and BAL (right) of control and vaccinated macaques after challenge. Bars indicate median viral loads. Dotted line indicates the limit of detection.

(C) Emerged viral variants found by viral sequencing in nasopharyngeal swabs at 3 dpe (left) and 5 dpe (middle) and BAL at 3 dpe. Colors indicate the open reading frames (ORFs) in which mutations were found, as depicted in the legend below. For a list of all identified variants, see Table S3. Note that the challenge stock already contained two viral variants, V367F in S protein and G251V in ORF3a.

(D) Lung CT scores of control and vaccinated macaques over the course of $14 \mathrm{dpe}$. CT score includes lesion type (scored from 0 to 3 ) and lesion volume (scored from 0 to 4) summed for each lobe. (E) Median lymphocyte counts over time in the blood of control and vaccinated macaques after challenge. Shaded area indicates the range. Symbols are the same as indicated in the left panel in (A). In $(A),(B)$, and $(E)$, groups were compared using the Mann-Whitney $U$ test $\left({ }^{\star} p<0.05 ;{ }^{\star *} p<0.01\right)$. See also Figures S5 and S6.

the S protein and G251V in ORF3a), which were later also found in the nasopharyngeal swabs and BAL samples. A median of six subclonal mutations were found per sample over all corresponding time points and anatomical sites, but no major differences were observed between control and vaccinated animals (Figure 6C). The majority of the variants observed in median sgRNA at day 3 dpe $\left(4.6 \log _{10}\right.$ versus $2.5 \log _{10} ; p=$ 0.0048) (Figures 6A and 6B).

An anamnestic response after challenge (i.e., an increase in $\mathrm{NAb}$ titers following challenge after vaccination) implies that vaccination is unable to induce sterilizing immunity. We observed no increase in median NAb titers in vaccinated macaques at 2, 3, and 6 weeks after challenge, in contrast to the control animals (Figure S6). Instead, NAb titers generally continued to wane, suggesting that vaccine-induced immunity rapidly controlled infection following challenge, preventing a boost of the immune system.

To assess the potential emergence of viral escape mutants in macaques after challenge, viral RNA in the challenge inoculum, nasal swabs at 3 and 5 dpe, and in BAL at 3 dpe was sequenced. Two main viral variants were identified in the inoculum (V367F in
ORF1ab were mostly missense mutations and consisted of a $\mathrm{C}$ $>$ T nucleotide change (Figure S6D; Table S3). A distinct variant in the $S$ sequence arose in two vaccinated macaques at day 3 in the nasopharyngeal swab but disappeared at day 5 post-challenge, suggesting that no NAb escape mutations emerged in vaccinated animals (Figure $6 \mathrm{C}$ ).

\section{Vaccinated cynomolgus macaques have reduced clinical manifestations}

Similar to previous observations (Maisonnasse et al., 2020; Yu et al., 2020), during the first $14 \mathrm{dpe}$, all contemporaneous and historical control animals showed mild pulmonary lesions characterized by nonextended ground-glass opacities (GGOs) detected by chest computed tomography (CT) (Figure 6D). By contrast, only three out of six vaccinated animals showed low 
Please cite this article in press as: Brouwer et al., Two-component spike nanoparticle vaccine protects macaques from SARS-CoV-2 infection, Cell (2021), https://doi.org/10.1016/j.cell.2021.01.035

\section{Cell \\ Article}

CT scores characteristic of mild and nonextended GGOs. Of note, the vaccinated macaque (MF6) with the highest CT score at day 14 showed the lowest $S$ protein and RBD binding titers, the lowest NAb titers, and the highest viral load and sgRNA at day 5 pe. Whereas all control animals experienced lymphopenia at 2 dpe, corresponding probably to the installation of the response to infection, lymphocyte counts remained stable after challenge for the vaccinated macaques (Figures 6E and S6), in agreement with the absence of detectable anamnestic response. Together, these data further support that vaccination with SARS-CoV-2 S-I53-50NPs reduces the severity of infection.

\section{DISCUSSION}

The development and distribution of a protective vaccine is paramount to bring the SARS-CoV-2 pandemic to a halt. Over the last few months, numerous vaccine candidates of different modalities have entered clinical and preclinical studies, including inactivated-virus-, DNA-, mRNA-, vector-, and protein-based vaccines (Klasse et al., 2020). Multivalent presentation of RSV and influenza antigens on two-component self-assembling protein nanoparticles has generated remarkably potent immune responses in non-human primates (Boyoglu-Barnum et al., 2020; Marcandalli et al., 2019). Recently, I53-50NPs presenting the RBD of SARS-CoV-2 induced potent NAb titers and significantly decreased viral loads in humanized mice (Walls et al., 2020b). This RBD-based SARS-CoV-2 vaccine, as well as an RSV vaccine using the 153-50 nanoparticle platform, is in clinical development (https://www.icosavax.com/), illustrating the feasibility of large-scale good manufacturing practices (GMP) production. Here, we show that I53-50NPs presenting 20 copies of prefusion SARS-CoV-2 $S$ protein induce robust NAb responses in mice, rabbits, and cynomolgus macaques. Vaccination of the latter prevented lymphopenia, reduced lung damage, and significantly reduced viral loads and replication in both the upper and lower respiratory tract, suggesting that SARS-CoV-2 S-I53-50NPs could reduce the risk of severe SARS-CoV-2-associated pathology in vaccinated humans and control viral shedding and transmission.

Evidence is mounting that NAb titers are the immunological correlate of protection for SARS-CoV-2 (Addetia et al., 2020; Yu et al., 2020), and it is increasingly accepted that a successful SARS-CoV-2 vaccine will need to induce potent NAb responses. We observed notable differences in NAb titers by our vaccine and previously described candidates, although comparisons may be biased by differences in vaccination schedules, assay variability, and inconsistencies in data presentation. Here, SARS-CoV2 S-I53-50NP-vaccinated macaques neutralized authentic virus with a median $I_{50}$ of $\sim 4,000$ after the final immunization, while $\mathrm{NAb}$ titers induced by adenovirus vector vaccines, including ChAdOx1 (van Doremalen et al., 2020) and Janssen (Mercado et al., 2020), DNA vaccines (Yu et al., 2020) and Inovio (Patel et al., 2020), and the inactivated vaccines Sinopharm (Wang et al., 2020) and Sinovacc (Gao et al., 2020), were at least 10-fold lower. However, NAb titers induced by SARS-CoV-2 S-153-50NPs were similar to the Moderna mRNA vaccine (Corbett et al., 2020) and lower than the Novavax and Clover Biopharmaceuticals protein vaccines (Guebre-Xabier et al., 2020; Liang et al., 2020).
Besides protecting an individual from COVID-19, a key component of an effective SARS-CoV-2 vaccine will be its ability to prevent viral transmission. Hence, sgRNA levels in the upper and lower airways are valuable endpoints in the evaluation of vaccine candidates. Similar to the Janssen and Novavax vaccines, vaccination with SARS-CoV-2 S-153-50NPs decreased median sgRNA to undetectable levels in the upper airways of all vaccinated animals within $5 \mathrm{dpe}$, while several other vaccines were unsuccessful in achieving such an effect (van Doremalen et al., 2020; Patel et al., 2020; Yu et al., 2020). One should consider that the Janssen and Novavax studies used 10- to 100 -fold lower challenge doses than used here. On the other hand, our regimen consisted of three immunizations, a number that may not be practical in the context of large-scale vaccination campaigns. However, even though three immunizations were used, the high NAb titers at week 6 indicate that two immunizations may be sufficient to confer protection. As in the Novavax study, the animals here were challenged 2 weeks after the final immunization (i.e., at peak NAb titer). It is therefore difficult to draw conclusions on the durability of the protection, but we note that SARS-CoV-2 memory B cells are expected to remain stable over a long period of time (Gaebler et al., 2021). Collectively, the rapid decrease in sgRNA levels, the low level of viral mutations in the $S$ protein, and the absence of an anamnestic response after challenge emphasize SARS-CoV-2 S-I53-50NP vaccination's profound ability to control infection and replication.

We propose two factors that may have been responsible for the potent humoral responses and protective efficacy by SARS-CoV2 S-153-50NPs. First, the high density of antigen on the I53-50NPs may have facilitated efficient activation of relevant NAb B cell lineages, which is in line with previous studies (Antanasijevic et al., 2020; Brouwer et al., 2019) and supported by B cell activation experiments described here. Second, by using an $S$ protein that has been stabilized in the prefusion state, we have likely improved the conformation of key NAb epitopes (such as the RBD) and decreased the exposure of non-NAb epitopes. Indeed, it has recently been shown that introduction of the two appropriately positioned prolines and removal of the polybasic-cleavage site significantly improved the protective ability of an S protein vaccine (Amanat et al., 2020). Nonetheless, these mutations alone might not be sufficient to generate stable trimeric $S$ proteins, and introducing additional stabilizing mutations, such as the previously described HexaPro mutations (Hsieh et al., 2020; Juraszek et al., 2021), may further improve the SARS-CoV-2 S-I53-50NPinduced humoral responses. Recently, nasal immunization has been shown to dramatically improve SARS-CoV-2 vaccine efficacy over intramuscular dosing (Hassan et al., 2020). Using this alternative administration route may allow SARS-CoV-2 S-I53$50 N P s$ to elicit protective NAb titers in the mucosa and could advance its protective efficacy toward fully sterilizing immunity.

\section{Limitations of study}

The data presented here show that three immunizations with SARS-CoV-2 S-I53-50NPs can induce protective immunity to a high-dose SARS-CoV-2 challenge. There are some limitations in our study that we should note. First, we challenged the macaques 2 weeks after the final immunization, generally corresponding to the peak of NAb titers. We therefore cannot 
ascertain that our vaccine would be as efficacious in the context of a delayed SARS-CoV-2 exposure. Second, our regimen included three immunizations (i.e., one more than vaccines currently in use or under consideration). Although we observed potent $\mathrm{NAb}$ responses after two immunizations, we cannot draw firm conclusions on the protective efficacy after two immunizations. Finally, recent months have seen the emergence of novel SARS-CoV-2 strains that may have the potential to evade $\mathrm{NAb}$ responses. Whether our vaccine is able to protect against these mutants warrants further investigation.

\section{STAR $\star$ METHODS}

Detailed methods are provided in the online version of this paper and include the following:

- KEY RESOURCES TABLE

- RESOURCE AVAILABILITY

Lead contact

O Materials availability

Data and code availability

- EXPERIMENTAL MODEL AND SUBJECT DETAILS

O Cell lines

Cynomolgus macaques

○ Rabbits

O Mice

O Patient sera

- METHOD DETAILS

O Construct design

- Protein expression and purification

- 153-50B.4PT1 expression and purification

O SARS-CoV-2 S-153-50NP assembly

O BN-PAGE analysis

O Negative-stain EM

O BLI assay

O Glycopeptide analysis by liquid chromatography-mass spectrometry

O Generation of B cells that stably express COVID-specific $B$ cell receptors

B cell activation assay

Animals and study designs

O Patient samples

O ELISAs

○ Pseudovirus neutralization assay

- Authentic virus neutralization assay

Protein coupling to Luminex beads

O Luminex assays

O SARS-CoV-2 S protein-specific CD4- and cTfh cell analysis using an activation induced marker (AIM) assay

O SARS-CoV-2 S protein and RBD-specific B cell analysis

o Viruses and cells

○ Virus quantification in cynomolgus macaque samples

O Chest computed tomography and image analysis

O ELISpot assays

$\bigcirc$ Viral sequencing

- QUANTIFICATION AND STATISTICAL ANALYSIS

\section{SUPPLEMENTAL INFORMATION}

Supplemental Information can be found online at https://doi.org/10.1016/j cell.2021.01.035.

\section{ACKNOWLEDGMENTS}

We thank B. Delache, S. Langlois, J. Demilly, N. Dhooge, P. Le Calvez, M. Potier, F. Relouzat, J.M. Robert, T. Prot, and C. Dodan for the non-human primate experiments; L. Bossevot, M. Leonec, L. Moenne-Loccoz, and J. Morin for the qRT-PCR and ELISpot assays and preparation of reagents; B. Fert for her help with the CT scans; M. Barendji, J. Dinh, and E. Guyon for the non-human primate sample processing; S. Keyser for the transports organization; N. Dimant and B. Targat for their help with the experimental studies in the context of COVID-19-induced constraints; F. Ducancel and Y. Gorin for their help with the logistics and safety management; and I. Mangeot for her help with resource management. Ramos B cells were obtained from Drs. L. Wu and V.N. KewalRaman through the NIH AIDS Reagent Program, Division of AIDS, NIAID, NIH. We thank A. McGuire for kindly sharing the pRRL.EuB29 lentiviral vector to transduce Ramos B cells. We thank P. Bieniasz for kindly sharing the pHIV$1_{\text {NL43 }} \Delta$ ENV-NanoLuc and SARS-CoV-2-S ${ }_{\Delta 19}$ plasmids and the 293T/ACE2 cell line. We thank $\mathrm{H}$. Nijhuis for sample transportation. We thank $\mathrm{A}$. Chung for sharing knowledge on the Luminex assay protocol and $B$. Wines and $\mathrm{M}$. Hogarth for sharing the Fc $\gamma R$ dimers. We thank Antoine Nougairede for sharing the plasmid used for the sgRNA assay standardization. Finally, we thank Dietmar Katinger and Philipp Mundsperger for providing the squalene emulsion and MPLA liposome adjuvants. Animal images in Figures 3 and 4 were created with BioRender.com. This work was supported by a Netherlands Organisation for Scientific Research (NWO) Vici grant (to R.W.S.); the Bill \& Melinda Gates Foundation through the Collaboration for AIDS Vaccine Discovery (CAVD) grants OPP1111923, OPP1132237, and INV-002022 (to R.W.S. and/or N.P.K.), INV-008352/OPP1153692 and OPP1196345/INV-008813 (to M.C.), and OPP1170236 (to A.B.W.); the Fondation Dormeur, Vaduz (R.W.S. and to M.J.v.G.) and Health-Holland PPS-allowance LSHM20040 (to M.J.v.G.); the University of Southampton Coronavirus Response Fund (M.C.); and the Netherlands Organisation for Health Research and Development ZONMW (B.L.H). M.J.v.G. is a recipient of an AMC Fellowship from Amsterdam UMC and a COVID-19 grant from the Amsterdam Institute for Infection and Immunity. R.W.S. and M.J.v.G. are recipients of support from the University of Amsterdam Proof of Concept fund (contract 200421) as managed by Innovation Exchange Amsterdam (IXA). The Infectious Disease Models and Innovative Therapies (IDMIT) research infrastructure is supported by the Programme Investissements d'Avenir, managed by the National Research Agency (ANR) under reference ANR-11-INBS-0008. The Fondation Bettencourt Schueller and the Region lle-de-France contributed to the implementation of IDMIT's facilities and imaging technologies. The non-human primate study received financial support from REACTing, the ANR (AM-CoV-Path), and the European Infrastructure TRANSVAC2 (730964). The funders had no role in study design, data collection, data analysis, data interpretation, or data reporting.

\section{AUTHOR CONTRIBUTIONS}

Conceptualization, methodology, validation, formal analysis, investigation, data curation, writing - original draft, visualization, and project administration, P.J.M.B., M.B., and P.M.; methodology, investigation, formal analysis, supervision, validation, writing - review \& editing, N.D.B.; conceptualization, methodology, investigation, and writing - original draft, M.G., M.C., M.d.G., J.D.A., and Y.W.; methodology, investigation, formal analysis, supervision, writing - review \& editing, R.M., V. Chesnais, and S.D.; formal analysis and writing - original draft, T.N.; investigation, formal analysis, and writing - review \& editing, J.L.; investigation and writing - original draft, G.K., J.M.G., H.T., and A.Z.M.; investigation, N.K., K.v.d.S., C.A.v.d.L., Y.A., I.B., J.A.B., M.P., E.E.S., M.J.v.B., T.G.C., J.v.S., N.M.A.O., and R.R.; conceptualization and writing original draft, K.S.; methodology, J.V.; conceptualization, methodology, supervision, and project administration, Y.U.v.d.V., and M.J.v.G.; resources and project administration, G.J.d.B.; supervision, V. Contreras; resources, supervision, and writing - review \& editing, C.C., R.H.T.F., B.L.H., N.P.K., M.C., 
and A.B.W.; resources and supervision, S.v.d.W. and E.G.; conceptualization, validation, resources, writing - review \& editing, supervision, project administration, and funding acquisition, R.L.G. and R.W.S.

\section{DECLARATION OF INTERESTS}

N.P.K. is a co-founder, shareholder, and chair of the scientific advisory board of Icosavax. The remaining authors declare no competing interests. Amsterdam UMC has filed a patent application concerning the SARS-CoV-2 mAbs used here (Brouwer et al., 2020). N.P.K. has a nonprovisional US patent (no. 14/930,792) related to $153-50$ (Bale et al., 2016).

Received: November 3, 2020

Revised: December 23, 2020

Accepted: January 21, 2021

Published: January 26, 2021

\section{REFERENCES}

Addetia, A., Crawford, K.H.D., Dingens, A., Zhu, H., Roychoudhury, P., Huang, M.L., Jerome, K.R., Bloom, J.D., and Greninger, A.L. (2020). Neutralizing antibodies correlate with protection from SARS-CoV-2 in humans during a fishery vessel outbreak with high attack rate. J. Clin. Microbiol. 58, e02107-e02120.

Agnandji, S.T., Lell, B., Fernandes, J.F., Abossolo, B.P., Methogo, B.G., Kabwende, A.L., Adegnika, A.A., Mordmüller, B., Issifou, S., Kremsner, P.G., et al.; RTS,S Clinical Trials Partnership (2012). A phase 3 trial of RTS,S/AS01 malaria vaccine in African infants. N. Engl. J. Med. 367, 2284-2295.

Amanat, F., Strohmeier, S., Rathnasinghe, R., Schotsaert, M., Coughlan, L., García-Sastre, A., and Krammer, F. (2020). Introduction of two prolines and removal of the polybasic cleavage site leads to optimal efficacy of a recombinant spike based SARS-CoV-2 vaccine in the mouse model. bioRxiv. https:// doi.org/10.1101/2020.09.16.300970.

Antanasijevic, A., Ueda, G., Brouwer, P.J.M., Copps, J., Huang, D., Allen, J.D., Cottrell, C.A., Yasmeen, A., Sewall, L.M., Bontjer, I., et al. (2020). Structural and functional evaluation of de novo-designed, two-component nanoparticle carriers for HIV Env trimer immunogens. PLoS Pathog. 16, e1008665.

Bachmann, M.F., and Jennings, G.T. (2010). Vaccine delivery: a matter of size, geometry, kinetics and molecular patterns. Nat. Rev. Immunol. 10, 787-796.

Bale, J.B., Gonen, S., Liu, Y., Sheffler, W., Ellis, D., Thomas, C., Cascio, D., Yeates, T.O., Gonen, T., King, N.P., and Baker, D. (2016). Accurate design of megadalton-scale two-component icosahedral protein complexes. Science 353, 389-394.

Boyoglu-Barnum, S., Ellis, D., Gillespie, R.A., Hutchinson, G.B., Park, Y.-J., Moin, S.M., Acton, O., Ravichandran, R., Murphy, M., Pettie, D., et al. (2020). Elicitation of broadly protective immunity to influenza by multivalent hemagglutinin nanoparticle vaccines. bioRxiv. https://doi.org/10.1101/2020. 05.30.125179.

Brouwer, P.J.M., Antanasijevic, A., Berndsen, Z., Yasmeen, A., Fiala, B., Bijl, T.P.L., Bontjer, I., Bale, J.B., Sheffler, W., Allen, J.D., et al. (2019). Enhancing and shaping the immunogenicity of native-like HIV-1 envelope trimers with a two-component protein nanoparticle. Nat. Commun. 10, 4272.

Brouwer, P.J.M., Caniels, T.G., van der Straten, K., Snitselaar, J.L., Aldon, Y. Bangaru, S., Torres, J.L., Okba, N.M.A., Claireaux, M., Kerster, G., et al. (2020). Potent neutralizing antibodies from COVID-19 patients define multiple targets of vulnerability. Science 369, 643-650.

Bruun, T.U.J., Andersson, A.C., Draper, S.J., and Howarth, M. (2018). Engineering a rugged nanoscaffold to enhance plug-and-display vaccination. ACS Nano 12, 8855-8866.

Cao, Y., Su, B., Guo, X., Sun, W., Deng, Y., Bao, L., Zhu, Q., Zhang, X., Zheng, Y., Geng, C., et al. (2020). Potent neutralizing antibodies against SARS-CoV-2 identified by high-throughput single-cell sequencing of convalescent patients' B cells. Cell 182, 73-84.e16.

Corbett, K.S., Flynn, B., Foulds, K.E., Francica, J.R., Boyoglu-Barnum, S., Werner, A.P., Flach, B., O'Connell, S., Bock, K.W., Minai, M., et al. (2020). Eval- uation of the mRNA-1273 vaccine against SARS-CoV-2 in nonhuman primates. N. Engl. J. Med. 383, 1544-1555.

Corman, V.M., Landt, O., Kaiser, M., Molenkamp, R., Meijer, A., Chu, D.K., Bleicker, T., Brünink, S., Schneider, J., Schmidt, M.L., et al. (2020). Detection of 2019 novel coronavirus (2019-nCoV) by real-time RT-PCR. Euro Surveill. 25, 2000045 .

de Taeye, S.W., Ozorowski, G., Torrents de la Peña, A., Guttman, M., Julien, J.-P., van den Kerkhof, T.L.G.M., Burger, J.A., Pritchard, L.K., Pugach, P. Yasmeen, A., et al. (2015). Immunogenicity of stabilized HIV-1 envelope trimers with reduced exposure of non-neutralizing epitopes. Cell 163, 1702-1715.

Dull, T., Zufferey, R., Kelly, M., Mandel, R.J., Nguyen, M., Trono, D., and Naldini, L. (1998). A third-generation lentivirus vector with a conditional packaging system. J. Virol. 72, 8463-8471.

Edge, P., and Bansal, V. (2019). Longshot enables accurate variant calling in diploid genomes from single-molecule long read sequencing. Nat. Commun. 10,4660

Feng, L., Wang, Q., Shan, C., Yang, C., Feng, Y., Wu, J., Liu, X., Zhou, Y., Jiang, R., Hu, P., et al. (2020). An adenovirus-vectored COVID-19 vaccine confers protection from SARS-COV-2 challenge in rhesus macaques. Nat. Commun. 11, 4207 .

Gaebler, C., Wang, Z., Lorenzi, J.C.C., Muecksch, F., Finkin, S., Tokuyama, M., Ladinsky, M., Cho, A., Jankovic, M., Schaefer-Babajew, D., et al. (2021) Evolution of antibody immunity to SARS-CoV-2. Nature. https://doi.org/10. 1038/s41586-021-03207-w.

Gao, Q., Bao, L., Mao, H., Wang, L., Xu, K., Yang, M., Li, Y., Zhu, L., Wang, N., Lv, Z., et al. (2020). Development of an inactivated vaccine candidate for SARS-CoV-2. Science 369, 77-81.

Gee, P., Lung, M.S.Y., Okuzaki, Y., Sasakawa, N., Iguchi, T., Makita, Y., Hozumi, H., Miura, Y., Yang, L.F., Iwasaki, M., et al. (2020). Extracellular nanovesicles for packaging of CRISPR-Cas9 protein and sgRNA to induce therapeutic exon skipping. Nat. Commun. 11, 1334.

Goddard, T.D., Huang, C.C., Meng, E.C., Pettersen, E.F., Couch, G.S., Morris, J.H., and Ferrin, T.E. (2018). UCSF ChimeraX: meeting modern challenges in visualization and analysis. Protein Sci. 27, 14-25.

Guebre-Xabier, M., Patel, N., Tian, J.-H., Zhou, B., Maciejewski, S., Lam, K., Portnoff, A.D., Massare, M.J., Frieman, M.B., Piedra, P.A., et al. (2020) NVX-CoV2373 vaccine protects cynomolgus macaque upper and lower airways against SARS-CoV-2 challenge. Vaccine 38, 7892-7896.

Hassan, A.O., Kafai, N.M., Dmitriev, I.P., Fox, J.M., Smith, B.K., Harvey, I.B., Chen, R.E., Winkler, E.S., Wessel, A.W., Case, J.B., et al. (2020). A singledose intranasal ChAd vaccine protects upper and lower respiratory tracts against SARS-CoV-2. Cell 183, 169-184.e13.

He, L., Lin, X., Wang, Y., Abraham, C., Sou, C., Ngo, T., Zhang, Y., Wilson, I.A., and Zhu, J. (2020). Self-assembling nanoparticles presenting receptor binding domain and stabilized spike as next-generation COVID-19 vaccines. bioRxiv. https://doi.org/10.1101/2020.09.14.296715.

Heit, A., Schmitz, F., Gerdts, S., Flach, B., Moore, M.S., Perkins, J.A., Robins, H.S., Aderem, A., Spearman, P., Tomaras, G.D., et al. (2017). Vaccination establishes clonal relatives of germinal center $\mathrm{T}$ cells in the blood of humans. J. Exp. Med. 214, 2139-2152.

Hsieh, C.-L., Goldsmith, J.A., Schaub, J.M., DiVenere, A.M., Kuo, H.-C., Javanmardi, K., Le, K.C., Wrapp, D., Lee, A.G., Liu, Y., et al. (2020). Structurebased design of prefusion-stabilized SARS-CoV-2 spikes. Science 369, 1501-1505

Juraszek, J., Rutten, L., Blokland, S., Bouchier, P., Voorzaat, R., Ritschel, T., Bakkers, M.J.G., Renault, L.L.R., and Langedijk, J.P.M. (2021). Stabilizing the closed SARS-CoV-2 spike trimer. Nat. Commun. 12 https://doi.org/10. 1038/s41467-020-20321-x.

Kanekiyo, M., Wei, C.-J., Yassine, H.M., McTamney, P.M., Boyington, J.C., Whittle, J.R.R., Rao, S.S., Kong, W.-P., Wang, L., and Nabel, G.J. (2013). Self-assembling influenza nanoparticle vaccines elicit broadly neutralizing H1N1 antibodies. Nature 499, 102-106. 
Kelly, H.G., Kent, S.J., and Wheatley, A.K. (2019). Immunological basis for enhanced immunity of nanoparticle vaccines. Expert Rev. Vaccines 18, 269-280.

Klasse, P.J., Nixon, D.F., and Moore, J.P. (2020). Immunogenicity of clinically relevant SARS-CoV-2 vaccines in non-human primates and humans. Preprints, 2020090166.

Koboldt, D.C., Zhang, Q., Larson, D.E., Shen, D., McLellan, M.D., Lin, L., Miller, C.A., Mardis, E.R., Ding, L., and Wilson, R.K. (2012). VarScan 2: somatic mutation and copy number alteration discovery in cancer by exome sequencing. Genome Res. 22, 568-576.

Koren, S., Walenz, B.P., Berlin, K., Miller, J.R., Bergman, N.H., and Phillippy, A.M. (2017). Canu: scalable and accurate long-read assembly via adaptive k-mer weighting and repeat separation. Genome Res. 27, 722-736.

Krarup, A., Truan, D., Furmanova-Hollenstein, P., Bogaert, L., Bouchier, P., Bisschop, I.J.M., Widjojoatmodjo, M.N., Zahn, R., Schuitemaker, H., McLellan, J.S., and Langedijk, J.P.M. (2015). A highly stable prefusion RSV F vaccine derived from structural analysis of the fusion mechanism. Nat. Commun. 6, 8143.

Lal, H., Poder, A., Campora, L., Geeraerts, B., Oostvogels, L., Vanden Abeele, C., and Heineman, T.C. (2018). Immunogenicity, reactogenicity and safety of 2 doses of an adjuvanted herpes zoster subunit vaccine administered 2, 6 or 12 months apart in older adults: results of a phase III, randomized, open-label, multicenter study. Vaccine 36, 148-154.

Lander, G.C., Stagg, S.M., Voss, N.R., Cheng, A., Fellmann, D., Pulokas, J., Yoshioka, C., Irving, C., Mulder, A., Lau, P.-W., et al. (2009). Appion: an integrated, database-driven pipeline to facilitate EM image processing. J. Struct. Biol. 166, 95-102.

Lescure, F.-X., Bouadma, L., Nguyen, D., Parisey, M., Wicky, P.-H., Behillil, S., Gaymard, A., Bouscambert-Duchamp, M., Donati, F., Le Hingrat, Q., et al. (2020). Clinical and virological data of the first cases of COVID-19 in Europe: a case series. Lancet Infect. Dis. 20, 697-706.

Li, H. (2018). Minimap2: pairwise alignment for nucleotide sequences. Bioinformatics 34, 3094-3100.

Liang, J.G., Su, D., Song, T.Z., Zeng, Y., Huang, W., and Wu, J. (2020). STrimer, a COVID-19 subunit vaccine candidate, induces protective immunity in nonhuman primates. bioRxiv. https://doi.org/10.1101/2020.09.24.311027. López-Sagaseta, J., Malito, E., Rappuoli, R., and Bottomley, M.J. (2015). Selfassembling protein nanoparticles in the design of vaccines. Comput. Struct. Biotechnol. J. 14, 58-68.

Ma, X., Zou, F., Yu, F., Li, R., Yuan, Y., Zhang, Y., Zhang, X., Deng, J., Chen, T., Song, Z., et al. (2020). Nanoparticle vaccines based on the receptor binding domain (RBD) and heptad repeat (HR) of SARS-CoV-2 elicit robust protective immune responses. Immunity 53, 1315-1330.e9.

Maisonnasse, P., Guedj, J., Contreras, V., Behillil, S., Solas, C., Marlin, R., Naninck, T., Pizzorno, A., Lemaitre, J., Gonçalves, A., et al. (2020). Hydroxychloroquine use against SARS-CoV-2 infection in non-human primates. Nature 585, 584-587.

Marcandalli, J., Fiala, B., Ols, S., Perotti, M., de van der Schueren, W., Snijder, J., Hodge, E., Benhaim, M., Ravichandran, R., Carter, L., et al. (2019). Induction of potent neutralizing antibody responses by a designed protein nanoparticle vaccine for respiratory syncytial virus. Cell 176, 1420-1431.e17.

McGuire, A.T., Dreyer, A.M., Carbonetti, S., Lippy, A., Glenn, J., Scheid, J.F., Mouquet, H., and Stamatatos, L. (2014). HIV antibodies. Antigen modification regulates competition of broad and narrow neutralizing HIV antibodies. Science 346, 1380-1383.

Mercado, N.B., Zahn, R., Wegmann, F., Loos, C., Chandrashekar, A., Yu, J., Liu, J., Peter, L., McMahan, K., Tostanoski, L.H., et al. (2020). Single-shot Ad26 vaccine protects against SARS-CoV-2 in rhesus macaques. Nature 586, 583-588.

Moyer, T.J., Zmolek, A.C., and Irvine, D.J. (2016). Beyond antigens and adjuvants: formulating future vaccines. J. Clin. Invest. 126, 799-808.

Okba, N.M.A., Müller, M.A., Li, W., Wang, C., GeurtsvanKessel, C.H., Corman, V.M., Lamers, M.M., Sikkema, R.S., de Bruin, E., Chandler, F.D., et al. (2020).
Severe acute respiratory syndrome coronavirus 2-specific antibody responses in coronavirus disease patients. Emerg. Infect. Dis. 26, 1478-1488.

Pallesen, J., Wang, N., Corbett, K.S., Wrapp, D., Kirchdoerfer, R.N., Turner, H.L., Cottrell, C.A., Becker, M.M., Wang, L., Shi, W., et al. (2017). Immunogenicity and structures of a rationally designed prefusion MERS-CoV spike antigen. Proc. Natl. Acad. Sci. USA 114, E7348-E7357.

Pan, F., Ye, T., Sun, P., Gui, S., Liang, B., Li, L., Zheng, D., Wang, J., Hesketh, R.L., Yang, L., and Zheng, C. (2020). Time course of lung changes at chest CT during recovery from coronavirus disease 2019 (COVID-19). Radiology 295, 715-721

Patel, A., Walters, J., Reuschel, E.L., Schultheis, K., Parzych, E., Gary, E.N., Maricic, I., Purwar, M., Eblimit, Z., Walker, S.N., et al. (2020). Intradermal-delivered DNA vaccine provides anamnestic protection in a rhesus macaque SARS-CoV-2 challenge model. bioRxiv. https://doi.org/10.1101/2020.07.28. 225649.

Potter, C.S., Chu, H., Frey, B., Green, C., Kisseberth, N., Madden, T.J., Miller, K.L., Nahrstedt, K., Pulokas, J., Reilein, A., et al. (1999). Leginon: a system for fully automated acquisition of 1000 electron micrographs a day. Ultramicroscopy $77,153-161$.

Powell, A.E., Zhang, K., Sanyal, M., Tang, S., Weidenbacher, P.A., Li, S., Pham, T.D., Pak, J.E., Chiu, W., and Kim, P.S. (2021). A single immunization with spike-functionalized ferritin vaccines elicits neutralizing antibody responses against SARS-CoV-2 in mice. ACS Cent. Sci. 7, 183-199.

Rogers, T.F., Zhao, F., Huang, D., Beutler, N., Burns, A., He, W.-T., Limbo, O., Smith, C., Song, G., Woehl, J., et al. (2020). Isolation of potent SARS-CoV-2 neutralizing antibodies and protection from disease in a small animal model. Science 369, 956-963.

Sanders, R.W., Vesanen, M., Schuelke, N., Master, A., Schiffner, L., Kalyanaraman, R., Paluch, M., Berkhout, B., Maddon, P.J., Olson, W.C., et al. (2002). Stabilization of the soluble, cleaved, trimeric form of the envelope glycoprotein complex of human immunodeficiency virus type 1. J. Virol. 76, 8875-8889.

Schmidt, F., Weisblum, Y., Muecksch, F., Hoffmann, H.-H., Michailidis, E., Lorenzi, J.C.C., Mendoza, P., Rutkowska, M., Bednarski, E., Gaebler, C., et al. (2020). Measuring SARS-CoV-2 neutralizing antibody activity using pseudotyped and chimeric viruses. J. Exp. Med. 217, e20201181.

Shang, J., Wan, Y., Luo, C., Ye, G., Geng, Q., Auerbach, A., and Li, F. (2020). Cell entry mechanisms of SARS-CoV-2. Proc. Natl. Acad. Sci. USA 117 11727-11734.

Shi, H., Han, X., Jiang, N., Cao, Y., Alwalid, O., Gu, J., Fan, Y., and Zheng, C. (2020). Radiological findings from 81 patients with COVID-19 pneumonia in Wuhan, China: a descriptive study. Lancet Infect. Dis. 20, 425-434.

Sliepen, K., Ozorowski, G., Burger, J.A., van Montfort, T., Stunnenberg, M., LaBranche, C., Montefiori, D.C., Moore, J.P., Ward, A.B., and Sanders, R.W. (2015). Presenting native-like HIV-1 envelope trimers on ferritin nanoparticles improves their immunogenicity. Retrovirology 12, 82.

Sliepen, K., Han, B.W., Bontjer, I., Mooij, P., Garces, F., Behrens, A.-J., Rantalainen, K., Kumar, S., Sarkar, A., Brouwer, P.J.M., et al. (2019). Structure and immunogenicity of a stabilized HIV-1 envelope trimer based on a groupM consensus sequence. Nat. Commun. 10, 2355.

Sungnak, W., Huang, N., Bécavin, C., Berg, M., Queen, R., Litvinukova, M., Talavera-López, C., Maatz, H., Reichart, D., Sampaziotis, F., et al.; HCA Lung Biological Network (2020). SARS-CoV-2 entry factors are highly expressed in nasal epithelial cells together with innate immune genes. Nat. Med. 26 , 681-687.

ter Brake, O., Konstantinova, P., Ceylan, M., and Berkhout, B. (2006). Silencing of HIV-1 with RNA interference: a multiple shRNA approach. Mol. Ther. 14, 883-892.

Tian, J.-H., Patel, N., Haupt, R., Zhou, H., Weston, S., Hammond, H., Logue, J., Pornoff, A., Norton, J., Guebre-Xabier, M., et al. (2021). SARS-CoV-2 spike glycoprotein vaccine candidate NVX-CoV2373 immunogenicity in baboons and protection in mice. Nat. Commun. 12, 372. 
Please cite this article in press as: Brouwer et al., Two-component spike nanoparticle vaccine protects macaques from SARS-CoV-2 infec-

tion, Cell (2021), https://doi.org/10.1016/j.cell.2021.01.035

\section{Cell}

Tokatlian, T., Read, B.J., Jones, C.A., Kulp, D.W., Menis, S., Chang, J.Y.H., Steichen, J.M., Kumari, S., Allen, J.D., Dane, E.L., et al. (2019). Innate immune recognition of glycans targets HIV nanoparticle immunogens to germinal centers. Science 363, 649-654.

Tyson, J.R., James, P., Stoddart, D., Sparks, N., Wickenhagen, A., Hall, G. Choi, J.H., Lapointe, H., Kamelian, K., Smith, A.D., et al. (2020). Improvements to the ARTIC multiplex PCR method for SARS-CoV-2 genome sequencing using nanopore. bioRxiv. https://doi.org/10.1101/2020.09.04.283077.

van Doremalen, N., Lambe, T., Spencer, A., Belij-Rammerstorfer, S., Purushotham, J.N., Port, J.R., Avanzato, V.A., Bushmaker, T., Flaxman, A., Ulaszewska, M., et al. (2020). ChAdOx1 nCoV-19 vaccine prevents SARS-CoV-2 pneumonia in rhesus macaques. Nature 586, 578-582.

Vella, L.A., Buggert, M., Manne, S., Herati, R.S., Sayin, I., Kuri-Cervantes, L. Bukh Brody, I., O’Boyle, K.C., Kaprielian, H., Giles, J.R., et al. (2019). T follicular helper cells in human efferent lymph retain lymphoid characteristics. J. Clin. Invest. 129, 3185-3200.

Veneziano, R., Moyer, T.J., Stone, M.B., Wamhoff, E.-C., Read, B.J., Mukherjee, S., Shepherd, T.R., Das, J., Schief, W.R., Irvine, D.J., and Bathe, M. (2020). Role of nanoscale antigen organization on B-cell activation probed using DNA origami. Nat. Nanotechnol. 15, 716-723.

Walls, A.C., Park, Y.-J., Tortorici, M.A., Wall, A., McGuire, A.T., and Veesler, D. (2020a). Structure, function, and antigenicity of the SARS-CoV-2 spike glycoprotein. Cell 181, 281-292.e6.
Walls, A.C., Fiala, B., Schäfer, A., Wrenn, S., Pham, M.N., Murphy, M., Tse, L.V., Shehata, L., O'Connor, M.A., Chen, C., et al. (2020b). Elicitation of potent neutralizing antibody responses by designed protein nanoparticle vaccines for SARS-CoV-2. Cell 183, 1367-1382.e17.

Wang, H., Zhang, Y., Huang, B., Deng, W., Quan, Y., Wang, W., Xu, W., Zhao, Y., Li, N., Zhang, J., et al. (2020). Development of an inactivated vaccine candidate, BBIBP-CorV, with potent protection against SARS-CoV-2. Cell 182, 713-721.e9.

Watanabe, Y., Allen, J.D., Wrapp, D., McLellan, J.S., and Crispin, M. (2020) Site-specific glycan analysis of the SARS-CoV-2 spike. Science 369, 330-333.

Wölfel, R., Corman, V.M., Guggemos, W., Seilmaier, M., Zange, S., Müller, M.A., Niemeyer, D., Jones, T.C., Vollmar, P., Rothe, C., et al. (2020). Virological assessment of hospitalized patients with COVID-2019. Nature 581, 465-469.

Wrapp, D., Wang, N., Corbett, K.S., Goldsmith, J.A., Hsieh, C.-L., Abiona, O. Graham, B.S., and McLellan, J.S. (2020). Cryo-EM structure of the 2019-nCoV spike in the prefusion conformation. Science 367, 1260-1263.

Yao, H., Song, Y., Chen, Y., Wu, N., Xu, J., Sun, C., Zhang, J., Weng, T., Zhang, Z., Wu, Z., et al. (2020). Molecular Architecture of the SARS-CoV-2 Virus. Cell 183, 730-738.e13.

Yu, J., Tostanoski, L.H., Peter, L., Mercado, N.B., McMahan, K., Mahrokhian, S.H., Nkolola, J.P., Liu, J., Li, Z., Chandrashekar, A., et al. (2020). DNA vaccine protection against SARS-CoV-2 in rhesus macaques. Science 369, 806-811. 
$\boldsymbol{D C e l l P r e s s}$

OPEN ACCESS

\section{STAR $\star$ METHODS}

\section{KEY RESOURCES TABLE}

\begin{tabular}{|c|c|c|}
\hline REAGENT or RESOURCE & SOURCE & IDENTIFIER \\
\hline \multicolumn{3}{|l|}{ Antibodies } \\
\hline COVA1-18 & Brouwer et al., 2020 & $\mathrm{~N} / \mathrm{A}$ \\
\hline COVA2-02 & Brouwer et al., 2020 & $\mathrm{~N} / \mathrm{A}$ \\
\hline COVA2-15 & Brouwer et al., 2020 & N/A \\
\hline COVA2-39 & Brouwer et al., 2020 & $\mathrm{~N} / \mathrm{A}$ \\
\hline COVA1-22 & Brouwer et al., 2020 & N/A \\
\hline Goat anti-mouse & Jackson Immunoresearch & Cat\# 115-005-003; RRID: AB_2338447 \\
\hline Goat anti-rabbit & Jackson Immunoresearch & Cat\# 111-035-144; RRID: AB_2307391 \\
\hline Goat anti-human & Jackson Immunoresearch & Cat\# 109-005-003; RRID: AB_2337532 \\
\hline goat anti-Human $\lg G \lambda$ & Southern Biotech & Cat\# 2070-01; RRID: AB_2795749 \\
\hline goat anti-Human $\lg G_{\kappa}$ & Southern Biotech & Cat\# 2060-01; RRID: AB_2795716 \\
\hline polyclonal macaque IgG & Molecular Innovations & Cat\# CY-GF-10MG; RRID: AB_10708230 \\
\hline polyclonal human IgG & NIH AIDS reagent program & Cat\# 3957 \\
\hline biotinylated mouse anti-monkey $\lg G$ & Southern Biotech & Cat\# 4700-08; RRID: AB_2796070 \\
\hline Goat-anti-human IgG-PE & Southern Biotech & Cat\# 2040-09; RRID: AB_2795648 \\
\hline Goat-anti human IgA-PE & Southern Biotech & Cat\# 2050-09; RRID: AB_2795707 \\
\hline Mouse-anti human IgM-PE & Southern Biotech & Cat\# 9020-09; RRID: AB_2796577 \\
\hline purified human $\mathrm{C} 1 \mathrm{q}$ & Complement Technologies & Cat\# A099 \\
\hline $\begin{array}{l}\text { mouse anti-human lgG-PE Cy7 (clone } \\
\text { G18-145) }\end{array}$ & BD PharMingen & Cat\# 561298; RRID: AB_10611712 \\
\hline $\begin{array}{l}\text { mouse anti-human IgM-APC (clone } \\
\text { MHM-88) }\end{array}$ & Biolegend & Cat\# 314510; RRID: AB_493011 \\
\hline SARS-CoV Nucleoprotein Rabbit PAb & SinoBiological & Cat\# 40143-T62 \\
\hline $\begin{array}{l}\text { Goat anti-Rabbit lgG }(\mathrm{H}+\mathrm{L}) \text { Alexa Fluor } \\
\text { Plus } 488\end{array}$ & Invitrogen & Cat\# A32731; RRID: AB_2866491 \\
\hline CD27 PE (clone M-T271) & BD biosciences & Cat\# 555441; RRID: AB_395834 \\
\hline CD20 PE-CF594 (clone 2H7) & BD biosciences & Cat\# 562295; RRID: AB_11153322 \\
\hline IgG PE-Cy7 (clone G18-145) & BD biosciences & Cat\# 561298; RRID: AB_10611712 \\
\hline IgM BV605 (clone MHM-88) & Biolegend & Cat\# 314524; RRID: AB_2562374 \\
\hline Fixable Viability Dye eF780 & eBioscience & Cat\# 65-0865-14 \\
\hline CXCR5 PE-Cy7 (clone MU5UBEE) & eBioscience & Cat\# 25-9185-41; RRID: AB_2573539 \\
\hline CD3 BUV395 (clone SP34-3) & BD biosciences & Cat\# 564117; RRID: AB_2738603 \\
\hline CD4 BUV496 (clone SK3) & BD biosciences & Cat\# 612937; RRID: AB_2870220 \\
\hline CD154 BV421 (clone TRAP1) & BD biosciences & Cat\# 563886; RRID: AB_2738466 \\
\hline CD69 BV785 (clone FN50) & Biolegend & Cat\# 310931; RRID: AB_2561370 \\
\hline CD40 (clone HB14) & Miltenyi Biotec & Cat\# 130-094-133; RRID: AB_10839704 \\
\hline \multicolumn{3}{|l|}{ Bacterial and virus strains } \\
\hline $\begin{array}{l}\text { SARS-CoV-2 virus (hCoV-19/France/ } \\
\text { IDF0372/2020 strain) }\end{array}$ & Lescure et al., 2020 & EPI_ISL_410720 (GISAID ID) \\
\hline $\begin{array}{l}\text { SARS-CoV-2 German isolate } \\
\text { (BavPat1/2020) }\end{array}$ & Christian Drosten & N/A \\
\hline \multicolumn{3}{|l|}{ Biological samples } \\
\hline Sera COVID-19 patients & Brouwer et al., 2020 & $\mathrm{~N} / \mathrm{A}$ \\
\hline
\end{tabular}


Please cite this article in press as: Brouwer et al., Two-component spike nanoparticle vaccine protects macaques from SARS-CoV-2 infection, Cell (2021), https://doi.org/10.1016/j.cell.2021.01.035

Cell

\begin{tabular}{|c|c|c|}
\hline \multicolumn{3}{|l|}{ Continued } \\
\hline REAGENT or RESOURCE & SOURCE & IDENTIFIER \\
\hline \multicolumn{3}{|l|}{ Chemicals, peptides, and recombinant proteins } \\
\hline Mass spectrometry grade trypsin & Promega & Cat\# V5280 \\
\hline Sequencing grade chymotrypsin & Promega & Cat\# V1061 \\
\hline Alpha lytic protease & Sigma Aldrich & Cat\# A6362 \\
\hline $\begin{array}{l}\text { Acetonitrile, } 80 \%, 20 \% \text { Water with } 0.1 \% \\
\text { Formic Acid, Optima LC/MS }\end{array}$ & Fisher Scientific & Cat\# 15431423 \\
\hline $\begin{array}{l}\text { Water with } 0.1 \% \text { Formic Acid (v/v), Optima } \\
\text { LC/MS Grade }\end{array}$ & Fisher Scientific & Cat\# LS118-212 \\
\hline Acetonitrile & Fisher Scientific & Cat\# 10489553 \\
\hline Trifluoroacetic acid & Fisher Scientific & Cat\# 10155347 \\
\hline Dithiothreitol & Sigma-Aldrich & Cat\# 43819 \\
\hline lodacetamide & Sigma-Aldrich & Cat\# I1149 \\
\hline PBS & Thermo Fisher & Cat\# 10010023 \\
\hline PEI MAX & Polysciences & Cat\# 24765-1 \\
\hline HRP-labeled streptavidin & Biolegend & Cat\# 405210 \\
\hline $3,3^{\prime}, 5,5^{\prime}$-tetranethylbenzidine & Sigma-Aldrich & Cat\# T4444 \\
\hline Squalene Emulsion adjuvant & Polymun Scientific & $\mathrm{N} / \mathrm{A}$ \\
\hline Polyinosinic-polycytidylic acid & Invivogen & Cat\# vac-pic \\
\hline MPLA liposomes & Polymun Scientific & $\begin{array}{l}\text { https://www.polymun.com/liposomes/ } \\
\text { reference-projects/ }\end{array}$ \\
\hline $\begin{array}{l}\text { 1-Ethyl-3-(3-dimethylaminopropyl) } \\
\text { carbodiimide }\end{array}$ & Thermo Fisher Scientific & Cat\# A35391 \\
\hline Sulfo-N-Hydroxysulfosuccinimide & Thermo Fisher Scientific & Cat\# A39269 \\
\hline Fc $\gamma$ Rlla human ectodomain dimer & Bruce Wines \& Mark Hogarth & $\mathrm{N} / \mathrm{A}$ \\
\hline Fc $\gamma$ RIlla human ectodomain dimer & Bruce Wines \& Mark Hogarth & $\mathrm{N} / \mathrm{A}$ \\
\hline Poly-L-Lysine Hydrobromide & Sigma-Aldrich & Cat\# P1399 \\
\hline Casein buffer & Thermo Scientific & Cat\# 37528 \\
\hline Lipofectamine 2000 & Life Technologies & Cat\# 11668-019 \\
\hline Penicillin & Sigma-Aldrich & Cat\# P3032-10MI \\
\hline Streptomycin & VWR & Cat\# 382-EU-100G \\
\hline Indo-1 & Invitrogen & Cat\# I1223 \\
\hline $\mathrm{CaCl} 2$ & Sigma-Aldrich & Cat\# C7902 \\
\hline Ionomycin & Invitrogen & Cat\# I24222 \\
\hline Staphylococcal enterotoxin B & Merck & Cat\# S4881-1MG \\
\hline Biotin (500 uM) & GeneCopoeia & Cat\# BI001 \\
\hline Streptavidin BB515 & $\mathrm{BD}$ & Cat\# 564453 \\
\hline Streptavidin AF647 & Biolegend & Cat\# 405237 \\
\hline Streptavidin BV421 & Biolegend & Cat\# 405226 \\
\hline Invitrogen UltraPure 0,5M EDTA, pH 8.0 & Thermo Fisher & Cat\# 15575020 \\
\hline \multicolumn{3}{|l|}{ Critical commercial assays } \\
\hline SSIV Reverse Transcriptase & Thermo Fisher & Cat\# 18090050 \\
\hline Q5 Hot Start DNA Polymerase & NEB & Cat\# M0494 \\
\hline Ligation Sequencing Kit & Nanopore & Cat\# SQK-LSK109 \\
\hline Nano-Glo Luciferase Assay System & Promega & Cat\# N1130 \\
\hline Nucleospin 96 Virus Core & Macherey-Nagel & Cat\# 740452.4 \\
\hline Superscript III platinum on step qRT-PCR & Thermo Fischer & Cat\# 11732088 \\
\hline Monkey IFN-g ELISPOT pro & Mabtech & Cat\# 3421M-2APT \\
\hline Biotin protein ligase & GeneCopoeia & Cat\# BI001 \\
\hline
\end{tabular}




\begin{tabular}{|c|c|c|}
\hline Continued & & \\
\hline REAGENT or RESOURCE & SOURCE & IDENTIFIER \\
\hline \multicolumn{3}{|l|}{ Experimental models: cell lines } \\
\hline FreeStyle $293 \mathrm{~F}$ cells & Thermo Fisher & Cat\# R79007 \\
\hline HEK293T/ACE2 cells & Schmidt et al., 2020 & $\mathrm{~N} / \mathrm{A}$ \\
\hline HEK293T cells & ATCC & Cat\# CRL-11268 \\
\hline Ramos B cells & $\begin{array}{l}\text { Obtained through the NIH AIDS Reagent } \\
\text { Program, Division of AIDS, NIAID, NIH; from } \\
\text { Drs. L. Wu and V. N. KewalRaman }\end{array}$ & $\mathrm{N} / \mathrm{A}$ \\
\hline VeroE6 & ATCC & ATCC $\circledast$ CRL 1586TM \\
\hline \multicolumn{3}{|l|}{ Experimental models: organisms/strains } \\
\hline BALB/cAnNCrl mice & Charles River Laboratories & $\mathrm{N} / \mathrm{A}$ \\
\hline New Zealand White rabbits & Covance Research Products, Inc & $\mathrm{N} / \mathrm{A}$ \\
\hline Cynomolgus macaques & Noveprim & N/A \\
\hline \multicolumn{3}{|l|}{ Oligonucleotides } \\
\hline Primers covid $19 \mathrm{~V} 3$ & ARTIC network & $\begin{array}{l}\text { https://artic.network/resources/ncov/ } \\
\text { ncov-amplicon-v3.pdf }\end{array}$ \\
\hline $\begin{array}{l}\text { RdRp-IP4 primers F- GGT AAC TGG TAT } \\
\text { GAT TTC G, R - CTG GTC AAG GTT AAT } \\
\text { ATA GG, probe P - TCA TAC AAA CCA CGC } \\
\text { CAG G }\end{array}$ & $\begin{array}{l}\text { https://www.who.int/docs/default-source/ } \\
\text { coronaviruse/ } \\
\text { real-time-rt-pcr-assays-for-the- } \\
\text { detection-of-sars-cov-2- } \\
\text { institut-pasteur-paris.pdf? } \\
\text { sfvrsn=3662fcb6_2 }\end{array}$ & N/A \\
\hline $\begin{array}{l}\text { sgLeadSARSCoV2-F } \\
\text { CGATCTCTTGTAGATCTGTTCTC, E- } \\
\text { Sarbeco-R primer } \\
\text { ATATTGCAGCAGTACGCACACA, E- } \\
\text { Sarbeco probe HEX- } \\
\text { ACACTAGCCATCCTTACTGCGCTTCG- } \\
\text { BHQ1 }\end{array}$ & Corman et al., 2020 & N/A \\
\hline \multicolumn{3}{|l|}{ Recombinant DNA } \\
\hline pHIV-1 ${ }_{\text {NL } 43} \Delta$ ENV-NanoLuc plasmid & Schmidt et al., 2020 & $\mathrm{~N} / \mathrm{A}$ \\
\hline SARS-CoV-2-S ${ }_{\Delta 19}$ plasmid & Schmidt et al., 2020 & $\mathrm{~N} / \mathrm{A}$ \\
\hline SARS-CoV-2 S pPPI4 plasmid & Brouwer et al., 2020 & N/A \\
\hline $\begin{array}{l}\text { SARS-CoV-2 S-153-50A.1NT1 pPPI4 } \\
\text { plasmid }\end{array}$ & This study & $\mathrm{N} / \mathrm{A}$ \\
\hline SARS-CoV-2 RBD pPPI4 plasmid & Brouwer et al., 2020 & $\mathrm{~N} / \mathrm{A}$ \\
\hline SARS-CoV-2 S-AVI pPPI4 plasmid & This Study & $\mathrm{N} / \mathrm{A}$ \\
\hline SARS-CoV-2 RBD-AVI pPPI4 plasmid & This Study & $\mathrm{N} / \mathrm{A}$ \\
\hline $\begin{array}{l}\text { pRRL EuB29 gl2-1261 } \\
\text { IgGTM.BCR.GFP.WPRE plasmid }\end{array}$ & McGuire et al., 2014 & $\mathrm{~N} / \mathrm{A}$ \\
\hline gblock COVA1-18 \& COVA2-15 & Integrated DNA Technologies & $\mathrm{N} / \mathrm{A}$ \\
\hline pMDLg & Dull et al., 1998 & Addgene Cat\# 12251 \\
\hline pRSV-Rev & Dull et al., 1998 & Addgene Cat\# 12259 \\
\hline pVSV-g & Gee et al., 2020 & Addgene Cat\# 138479 \\
\hline \multicolumn{3}{|l|}{ Software and algorithms } \\
\hline Empower 3.0 & Waters & $\mathrm{N} / \mathrm{A}$ \\
\hline Masslynx v4.1 & Waters & $\mathrm{N} / \mathrm{A}$ \\
\hline Driftscope version 2.8 & Waters & $\mathrm{N} / \mathrm{A}$ \\
\hline Byos $^{\mathrm{TM}}$ (Version 3.9) & Protein Metrics Inc. & $\mathrm{N} / \mathrm{A}$ \\
\hline GraphPad Prism v8 & GraphPad & $\mathrm{N} / \mathrm{A}$ \\
\hline XCalibur Version v4.2 & Thermo Fisher & $\mathrm{N} / \mathrm{A}$ \\
\hline
\end{tabular}


Please cite this article in press as: Brouwer et al., Two-component spike nanoparticle vaccine protects macaques from SARS-CoV-2 infection, Cell (2021), https://doi.org/10.1016/j.cell.2021.01.035

Cell

\begin{tabular}{|c|c|c|}
\hline \multicolumn{3}{|l|}{ Continued } \\
\hline REAGENT or RESOURCE & SOURCE & IDENTIFIER \\
\hline Orbitrap Fusion Tune application v3.1 & Thermo Fisher & $\mathrm{N} / \mathrm{A}$ \\
\hline Flowjo v10 & Flowjo & $\mathrm{N} / \mathrm{A}$ \\
\hline UCSF ChimeraX & Goddard et al., 2018 & N/A \\
\hline GraphPad Prism v7 & GraphPad & $\mathrm{N} / \mathrm{A}$ \\
\hline Canu & Koren et al., 2017 & https://github.com/marbl/canu \\
\hline Minimap2 & Li, 2018 & https://github.com/lh3/minimap2 \\
\hline Varscan & Koboldt et al., 2012 & http://varscan.sourceforge.net/ \\
\hline Longshot & Edge and Bansal, 2019 & https://github.com/pjedge/longshot \\
\hline INTELLISPACE PORTAL 8 software & Philips healthcare & $\begin{array}{l}\text { https://www.philips.sa/en/healthcare/ } \\
\text { product/HC881062/ } \\
\text { intellispace-portal-80-all-your- } \\
\text { advanced-analysis-needs-one- } \\
\text { comprehensive-solution }\end{array}$ \\
\hline ImageQuant TL 8.2 image analysis software & GE Healthcare & $\mathrm{N} / \mathrm{A}$ \\
\hline \multicolumn{3}{|l|}{ Other } \\
\hline $\begin{array}{l}\text { EasySpray PepMap RSLC C18 column } \\
(75 \mu \mathrm{m} \times 75 \mathrm{~cm})\end{array}$ & Thermo Fisher Scientific & Cat\# ES805 \\
\hline C18 ZipTip & Merck Milipore & Cat\# ZTC18S008 \\
\hline $\begin{array}{l}\text { Vivaspin 500, } 3 \text { kDa MWCO, } \\
\text { Polyethersulfone }\end{array}$ & Sigma-Aldrich & Cat\# GE28-9322-18 \\
\hline $\begin{array}{l}\text { PepMap100 C18 3UM 75UM×2CM } \\
\text { Nanoviper }\end{array}$ & Thermo Scientific & Cat\# 164946 \\
\hline Ni-NTA agarose & QIAGEN & Cat\# 30210 \\
\hline Ni-NTA HighSorb plates & QIAGEN & Cat\# 35061 \\
\hline NuPAGE $4-12 \%$ Bis-Tris gels & Thermo Fisher & Cat\# NP0321BOX \\
\hline Superose 6 increase 10/300 GL & Sigma-Aldrich & Cat\# GE29-0915-96 \\
\hline Econo-column chromatography columns & BIO RAD & Cat\# 7371512 \\
\hline NGC chromatography system & BIO RAD & $\mathrm{N} / \mathrm{A}$ \\
\hline Octet K2 system & Sartorius (FortéBio) & N/A \\
\hline Octet Biosensors: Protein A & Sartorius (FortéBio) & Cat\# 18-5010 \\
\hline $\begin{array}{l}\text { Vivaspin } 20,100.000 \mathrm{kDa} \mathrm{MWCO} \text {, } \\
\text { Polyethersulfone }\end{array}$ & Sigma-Aldrich & Cat\# GE28-9323-63 \\
\hline Nucleobond Xtra Maxi kit & Macherey-Nagel & Cat\# 740414.50 \\
\hline Fast Digest BamHI & Thermo Scientific & Cat\# FD0054 \\
\hline Fast Digest Green buffer 10x & Thermo Scientific & Cat\# B72 \\
\hline Fast Digest Pstl & Thermo Scientific & Cat\# FD0614 \\
\hline Magplex Microspheres & Luminex & Cat\# MC10043-01 \\
\hline Streptavidin-PE & Thermo Fisher Scientific & Cat\# 12-4317-87 \\
\hline Bioplex 200 & Bio-Rad & Cat\# 171000205 \\
\hline FreeStyle 293 Expression medium & Thermo Scientific & Cat\# 12338018 \\
\hline DMEM & Sigma-Aldrich & Cat\# D6429-500ML \\
\hline Glutamax supplement & Thermo Fisher & Cat\# 35050061 \\
\hline $\begin{array}{l}\text { High-binding plates: Half-area 96-well } \\
\text { polystyrene high-binding microplate }\end{array}$ & Greiner & Cat\# 675061 \\
\hline Steritop Filter Units & Merckmillipore & Cat\# C3239 \\
\hline Glomax & Turner BioSystems & Model\# 9101-002 \\
\hline Microplate 96 well half area white & Greiner bio-one & Cat\# 675074 \\
\hline VTM medium & CDC, DSR-052-01 & $\begin{array}{l}\text { https://www.cdc.gov/coronavirus/ } \\
\text { 2019-ncov/downloads/ } \\
\text { Viral-Transport-Medium.pdf }\end{array}$ \\
\hline
\end{tabular}

(Continued on next page) 
Please cite this article in press as: Brouwer et al., Two-component spike nanoparticle vaccine protects macaques from SARS-CoV-2 infection, Cell (2021), https://doi.org/10.1016/j.cell.2021.01.035

$\infty$ CellPress

OPEN ACCESS

\begin{tabular}{lll}
\hline Continued & & \\
\hline REAGENT or RESOURCE & SOURCE & IDENTIFIER \\
\hline RPMI Medium 1640 & GIBCO & Cat\# 21875-034 \\
Hanks' Balanced Salt Solution (HBSS) & GIBCO & Cat\# 14175-053 \\
FACS Aria-II SORP & BD biosciences & N/A \\
LSR Fortessa & BD biosciences & N/A \\
Amersham Typhoon Biomolecular Imager & GE Healthcare & Amersham Typhoon Biomolecular Imager \\
BD micro-fine+; U-100 Insulin 0.5 ml; 0,33 & BD biosciences & Cat\# 037-7614 \\
(29G)x12,7 mm & & \\
Microvette CB300 K2E & Sarstedt & Cat\# 16.444.100 \\
HEPES (1M, GIBCO) & Thermofisher scientific & Cat\# 15630106 \\
Greiner CELLSTAR 96 well plates round & Merck & Cat\# M9436 \\
bottom clear wells & & \\
Lemo21 (DE3) & New England Biolabs & Cat\# C2528J \\
Ni Sepharose 6 FF & Cytiva & Cat\#17531808 \\
AKTA Avant150 FPLC system & Cytiva & N/A \\
Superdex 200 Increase SEC column & Cytiva & Cat\# 28-9909-44 \\
\hline
\end{tabular}

\section{RESOURCE AVAILABILITY}

Lead contact

Further information and requests for resources and reagents should be directed to and will be fulfilled by the lead contact, Rogier W. Sanders (r.w.sanders@amsterdamumc.nl).

Materials availability

All reagents will be made available on request after completion of a Materials Transfer Agreement.

Data and code availability

The raw data supporting the findings of the study are available from the corresponding authors upon reasonable request.

\section{EXPERIMENTAL MODEL AND SUBJECT DETAILS}

\section{Cell lines}

HEK293F (Life Technologies) and HEK293T (ATCC CRL-11268) are human embryonic kidney cell lines transformed for increased production of recombinant protein or retrovirus. HEK293F cells are adapted to grow in suspension. HEK293F cells were cultured at $37^{\circ} \mathrm{C}$ with $8 \% \mathrm{CO}_{2}$ and shaking at $125 \mathrm{rpm}$ in 293FreeStyle expression medium (Life Technologies). HEK293T cells were cultured at $37^{\circ} \mathrm{C}$ with $5 \% \mathrm{CO}_{2}$ in flasks with DMEM supplemented with $10 \%$ fetal bovine serum (FBS), streptomycin (100 $\left.\mu \mathrm{g} / \mathrm{mL}\right)$ and penicillin $\left(100 \mathrm{U} / \mathrm{mL}\right.$ ). VeroE6 (ATCC CRL-1586) is a kidney epithelial cell from African green monkeys. VeroE6 cells were cultured at $37^{\circ} \mathrm{C}$ with $5 \% \mathrm{CO}_{2}$ in DMEM supplemented with or without streptomycin $(100 \mu \mathrm{g} / \mathrm{mL})$ and penicillin $(100 \mathrm{U} / \mathrm{mL})$ and with or without 5 or $10 \%$ FBS, and with or without TPCK-trypsin. HEK293T/ACE2 cells (Schmidt et al., 2020) are a human embryonic kidney cell line expressing human angiotensin-converting enzyme 2 . HEK293T/ACE2 cells were cultured at $37^{\circ} \mathrm{C}$ with $5 \% \mathrm{CO}_{2}$ in flasks with DMEM supplemented with $10 \% \mathrm{FBS}$, streptomycin $(100 \mu \mathrm{g} / \mathrm{mL})$ and penicillin $(100 \mathrm{U} / \mathrm{mL})$. Ramos is a human Burkitt's lymphoma cell line that has B lymphocyte characteristics. Ramos $\mathrm{B}$ cells were cultured at $37^{\circ} \mathrm{C}$ with $5 \% \mathrm{CO}_{2}$ in RPMI supplemented with $10 \%$ FBS, streptomycin $(100 \mu \mathrm{g} / \mathrm{mL})$ and penicillin $(100 \mathrm{U} / \mathrm{mL})$.

\section{Cynomolgus macaques}

Female cynomolgus macaques (Macaca fascicularis), aged 56-66 months and originating from Mauritian AAALAC certified breeding centers were used in this study. All animals were housed in IDMIT infrastructure facilities (CEA, Fontenay-aux-roses), under BSL-2 and BSL-3 containment when necessary (Animal facility authorization \#D92-032-02, Préfecture des Hauts de Seine, France) and in compliance with European Directive 2010/63/EU, the French regulations and the Standards for Human Care and Use of Laboratory Animals, of the Office for Laboratory Animal Welfare (OLAW, assurance number \#A5826-01, US). The protocols were approved by the institutional ethical committee "Comité d'Ethique en Expérimentation Animale du Commissariat à l'Energie Atomique et aux Energies Alternatives" (CEtEA \#44) under statement number A20-011. The study was authorized by the "Research, Innovation and Education Ministry" under registration number APAFIS\#24434-2020030216532863v1. 


\section{Rabbits}

Female New Zealand White rabbits of $2.5-3 \mathrm{~kg}$ from multiple litters were used. Animals were sourced and housed at Covance Research Products, Inc. (Denver, PA, USA) and immunizations were performed under permits with approval number C0084-20. Immunization procedures complied with all relevant ethical regulations and protocols of the Covance Institutional Animal Care and Use Committee.

\section{Mice}

Female BALB/cAnNCrl mice, aged 8 weeks, were ordered from Charles River Laboratories and housed at the Animal Research Institute Amsterdam under BSL-2 conditions. All experiments were performed in accordance with the Dutch Experiment on Animals Act and were approved by the Animal Ethics Committee of the Amsterdam UMC (Permit number 17-4045).

\section{Patient sera}

Sera were collected from male and female patients aged between 18 and 75 years through the COVID-19 Specific Antibodies (COSCA) study, which was performed at the Amsterdam University Medical Centre, location AMC, the Netherlands under approval of the local ethical committee of the AMC (NL 73281.018.20) (Brouwer et al., 2020).

\section{METHOD DETAILS}

\section{Construct design}

To create the SARS-CoV-2 S-I53-50A.1NT1 construct, the previously described pPPI4 plasmid encoding the prefusion stabilized SARSCoV-2 S protein (Brouwer et al., 2020) was digested with Pstl and BamHI and ligated in a Pstl-BamHI-digested pPPI4 plasmid encoding a modified I53-50A.1NT1 sequence. The original I53-50A.1NT1 plasmid was described previously (Brouwer et al., 2019). Modifications constitute the introduction of GSLEHHHHHH after the final residue to introduce a C-terminal histidine-tag. To generate $S$ proteins for FACS analyses, the prefusion S protein sequence was cloned into a pPPI4 backbone encoding a I53-50A.1NT1 sequence that had an Avi-and histidine-tag after the final residue. The RBD probe was generated by digesting this plasmid with Pstl-BamHI and introducing, by Gibson assembly, a gene encoding the RBD (residues 319-541) directly downstream of a TPA leader sequence. For ELISAs, Luminex assays, and ELISpots, histidine-tagged versions of SARS-CoV-2 S protein and RBD were produced by cloning the aforementioned sequences into a pPPI4 plasmid containing a hexahistidine tag using Pstl and BamHI digestion and ligation.

\section{Protein expression and purification}

All constructs were expressed by transient transfection of HEK293F cells (Invitrogen) maintained in Freestyle medium (Life Technologies) at a density of 0.8-1.2 million cells $/ \mathrm{mL}$. On the day of transfection, a mix of PElmax $(1 \mu \mathrm{g} / \mu \mathrm{L})$ with expression plasmids $(312.5 \mu \mathrm{g} / \mathrm{L})$ in a 3:1 ratio in OptiMEM (GIBCO) were added to the cells. Six days post transfection, supernatants were centrifuged for $30 \mathrm{~min}$ at $4000 \mathrm{rpm}$, filtered using $0.22 \mu \mathrm{m}$ Steritop filters (Merck Millipore), and subjected to affinity purification using Ni-NTA agarose beads. Protein eluates were then concentrated and buffer exchanged to PBS using Vivaspin filters with the appropriate molecular weight cutoff (GE Healthcare). Protein concentrations were determined by the Nanodrop method using the proteins peptidic molecular weight and extinction coefficient as determined by the online ExPASy software (ProtParam).

\section{3-50B.4PT1 expression and purification}

Lemo21 (DE3) (NEB) cells expressing 153-50B.4PT1 were grown in a 10L BioFlo 320 Fermenter (Eppendorf) or a 2L shake flask. Cells were grown in LB (10 g Tryptone, $5 \mathrm{~g}$ Yeast Extract, $10 \mathrm{~g} \mathrm{NaCl})$ at $37^{\circ} \mathrm{C}$ to an OD600 of 0.8 . After the cells were induced with $1 \mathrm{mM}$ of IPTG, temperature was reduced to $18^{\circ} \mathrm{C}$ and cells were grown for $16 \mathrm{~h}$. The cells were then lysed in $50 \mathrm{mM} \mathrm{Tris,} 500 \mathrm{mM} \mathrm{NaCl}, 30 \mathrm{mM}$ imidazole, $1 \mathrm{mM}$ PMSF, $0.75 \%$ CHAPS using a Microfluidics M110P at 18,000 psi. Lysate was centrifuged at 24,000 $\mathrm{g}$ for $30 \mathrm{minutes}$. Clarified lysate was next applied to a Ni Sepharose 6 FF column (Cytiva) linked to an AKTA Avant150 FPLC system (Cytiva) for immobilized metal affinity chromatography. 153-50B.4PT1 was eluted using a $30 \mathrm{mM}$ to $500 \mathrm{mM}$ imidazole linear gradient in $50 \mathrm{mM}$ Tris $\mathrm{pH} 8,500 \mathrm{mM} \mathrm{NaCl}$ and $0.75 \%$ CHAPS. Fractions containing I53-50B.4PT1 were pooled, concentrated using centrifugal filters with a $10,000 \mathrm{kDa}$ cutoff (Millipore), sterilized and applied to a Superdex 200 Increase 10/300 (Cytvia) for further purification. Batches were tested for endotoxin levels before use.

\section{SARS-CoV-2 S-I53-50NP assembly}

Ni-NTA eluates of SARS-CoV-2 S-I53-50A.1NT1 (expressed as described above) were buffer exchanged to Tris-buffer-saline (TBS), sterile filtered $(0.22 \mu \mathrm{m})$ and applied to a Superose 6 increase 10/300 GL column (GE healthcare) linked to a NGC chromatography system (Bio-Rad) in TBS supplemented with 5\% glycerol. Size exclusion fractions between 12-14 mL were pooled and an equimolar amount of I53-50B.4PT1 was added. After an overnight incubation at $4^{\circ} \mathrm{C}$, the assembly mix was applied to a Superose 6 increase $10 /$ $300 \mathrm{GL}$ column in TBS+5\% glycerol to remove unassembled components. Fractions corresponding to assembled SARS-CoV-2 S153-50NPs (8.5-9.5 mL) were collected and concentrated using Vivaspin columns with a molecular weight cutoff of 10,000 kDa (GE Healthcare). Protein concentrations were determined by the Nanodrop method using the proteins peptidic molecular weight and extinction coefficient as determined by the online ExPASy software (ProtParam). 


\section{BN-PAGE analysis}

BN-PAGE was performed as described previously (de Taeye et al., 2015). Briefly, $2.5 \mu \mathrm{g}$ of $\mathrm{S}$ protein was mixed with loading dye and run on a $4 \%-12 \%$ Bis-Tris NuPAGE gel (Invitrogen).

\section{Negative-stain EM}

SARS-CoV-2 S-153-50NPs were added to carbon-covered 400 mesh copper grids and stained with $2 \%$ uranyl formate. Micrographs were imaged on a Tecnai F12 Spirit microscope with a 4k FEI Eagle CCD. Leginon (Potter et al., 1999) and Appion (Lander et al., 2009) were used to collect and process micrographs.

\section{BLI assay}

SARS-CoV-2 S-153-50A.1NT1 and SARS-CoV-2 S-153-50NP were diluted to $100 \mathrm{nM}$ and 5nM, respectively, in BLI running buffer (PBS/0.1\% bovine serum albumin/0.02\% Tween20) and antibody binding was assessed using a ForteBio Octet K2. The binding assays were performed at $30^{\circ} \mathrm{C}$ and with agitation set at $1000 \mathrm{rpm}$. Antibody was loaded on protein A sensors (ForteBio) at $10 \mu \mathrm{g} / \mathrm{mL}$ in running buffer until a binding threshold of $1 \mathrm{~nm}$ was reached. Association and dissociation were measured for $300 \mathrm{~s}$.

\section{Glycopeptide analysis by liquid chromatography-mass spectrometry}

Gycopeptide analysis was essentially performed as described previously (Watanabe et al., 2020). A $30 \mu \mathrm{g}$ aliquot of SARS-CoV-2 SI53-50A.1NT1 was denatured, alkylated, reduced and cleaved by the proteases trypsin, chymotrypsin and alpha-lytic protease. Clean-up of the resulting peptide/glycopeptides was performed using C18 Zip-tips and the sample was analyzed by nanoLC-ESI MS with an Easy-nLC 1200 (Thermo Fisher Scientific) system coupled to a Fusion mass spectrometer (Thermo Fisher Scientific) using higher energy collision-induced dissociation (HCD) fragmentation. Peptides were separated using an EasySpray PepMap RSLC C18 column $(75 \mu \mathrm{m} \times 75 \mathrm{~cm})$. Glycopeptide fragmentation data were extracted from the raw file using Byonic ${ }^{\mathrm{TM}}$ (Version 3.5) and Byologic $^{\mathrm{TM}}$ software (Version 3.5; Protein Metrics Inc.).

\section{Generation of B cells that stably express COVID-specific B cell receptors}

The B cell specific expression plasmid was constructed by exchanging the gl2-1261 gene of the pRRL EuB29 gl2-1261 IgGTM.BCR.GFP.WPRE plasmid (McGuire et al., 2014) with heavy and light chain genes of either COVA1-18 and COVA2-15 using Gibson assembly (Integrated DNA Technologies). The production of lentivirus in HEK293T and the subsequent transduction was conducted as described elsewhere (ter Brake et al., 2006). In short, lentiviruses were produced by co-transfecting the expression plasmid with pMDL, pVSV-g and pRSV-Rev into HEK293T cells using lipofectamine 2000 (Invitrogen). Two days post transfection, IgM-negative Ramos B cells cultured in RPMI (GIBCO) supplemented with $10 \%$ fetal calf serum, streptomycin $(100 \mu \mathrm{g} / \mathrm{mL})$ and penicillin $(100 \mathrm{U} / \mathrm{mL})(\mathrm{RPMl}++)$ were transduced with filtered $(0.45 \mu \mathrm{m})$ and concentrated $(100 \mathrm{kDa}$ molecular weight cutoff, GE Healthcare) HEK293T supernatant. Seven days post transduction, BCR-expressing B cells were FACS sorted on IgG and GFP double-positivity using a FACS Aria-II SORP (BD biosciences). B cells were then expanded and cultured indefinitely.

\section{B cell activation assay}

B cell activation experiments of SARS-CoV-2 S protein-specific Ramos B cells were performed as previously described (Brouwer et al., 2019; Sliepen et al., 2019). In short, 4 million cells $/ \mathrm{mL}$ in RPMI++ were loaded with $1.5 \mu \mathrm{M}$ of the calcium indicator Indo-1 (Invitrogen) for $30 \mathrm{~min}$ at $37^{\circ} \mathrm{C}$, washed with Hank's Balance Salt Solution supplemented with $2 \mathrm{mM} \mathrm{CaCl}$, followed by another incubation of $30 \mathrm{~min}$ at $37^{\circ} \mathrm{C}$. Antigen-induced $\mathrm{Ca}^{2+}$ influx of COVID-specific B cells were monitored on a LSR Fortessa (BD Biosciences) by measuring the $379 / 450 \mathrm{~nm}$ emission ratio of Indo-1 fluorescence upon UV excitation. Following $30 \mathrm{~s}$ of baseline measurement, aliquots of 1 million cells $/ \mathrm{mL}$ were then stimulated for $100 \mathrm{~s}$ at RT with either $5 \mu \mathrm{g} / \mathrm{mL}, 1 \mu \mathrm{g} / \mathrm{mL}, 200 \mathrm{ng} / \mathrm{mL}$ or $40 \mathrm{ng} / \mathrm{mL}$ of SARSCoV-2 S-I53-50A.1NT1 or the equimolar amount presented on I53-50NPs. Ionomycin (Invitrogen) was added to a final concentration of $1 \mathrm{mg} / \mathrm{mL}$ to determine the maximum Indo-1-fluorescence. Kinetics analyses were performed using FlowJo v10.7.

\section{Animals and study designs}

Cynomolgus macaques were randomly assigned in two experimental groups. The vaccinated group $(n=6)$ received 50 ug of SARSCoV-2 S-153-50NP adjuvanted with $500 \mu \mathrm{g}$ of MPLA liposomes (Polymun Scientific, Klosterneuburg, Austria) diluted in PBS at weeks 0,4 and 10 , while control animals $(n=4)$ received no vaccination. Vaccinated animals were sampled in blood, nasal swabs and saliva at weeks $0,2,4,6,8,10$ and 12 . At week 12, all animals were exposed to a total dose of $10^{6}$ pfu of SARS-CoV-2 virus (hCoV-19/ France/ IDF0372/2020 strain; GISAID EpiCoV platform under accession number EPI_ISL_406596) via the combination of intranasal and intra-tracheal routes $(0,25 \mathrm{~mL}$ in each nostril and $4,5 \mathrm{~mL}$ in the trachea, i.e., a total of $5 \mathrm{~mL}$; day 0$)$, using atropine $(0.04 \mathrm{mg} / \mathrm{kg})$ for pre-medication and ketamine $(5 \mathrm{mg} / \mathrm{kg})$ with medetomidine $(0.042 \mathrm{mg} / \mathrm{kg})$ for anesthesia. Saliva, as well as nasopharyngeal, tracheal and rectal swabs, were collected at days 1, 2, 3, 4, 5, 6, 10, 14 and 21 days past exposure (dpe) while blood was taken at days 2, 4, 6, 10,14 and $21 \mathrm{dpe}$. Bronchoalveolar lavages (BAL) were performed using $50 \mathrm{~mL}$ sterile saline on $3 \mathrm{dpe}$. A single BAL was performed at $3 \mathrm{dpe}$ in order to be close to the peak of viral replication and to be able to observe a difference between the vaccinated and control groups. In our earlier study (Maisonnasse et al., 2020), we found that at later time-points, viral loads in the BAL were very low or negative. Chest CT was performed at baseline and on 3, 7 and $14 \mathrm{dpe}$ in anesthetized animals using tiletamine $(4 \mathrm{mg} / \mathrm{kg})$ and zolazepam 
Please cite this article in press as: Brouwer et al., Two-component spike nanoparticle vaccine protects macaques from SARS-CoV-2 infection, Cell (2021), https://doi.org/10.1016/j.cell.2021.01.035
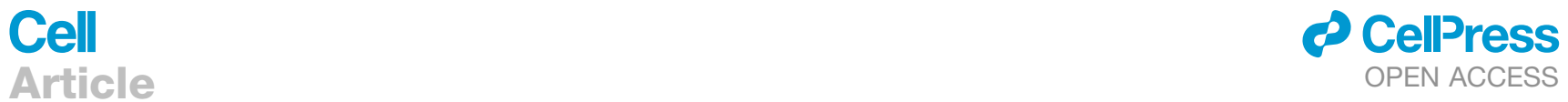

(4 mg/kg). Blood cell counts, haemoglobin and hematocrit were determined from EDTA blood using a HMX A/L analyzer (Beckman Coulter).

Female New Zealand White rabbits were given two intramuscular immunizations, one in each quadricep, at weeks 0,4 , and 12 . The immunization mixture involved $39 \mu \mathrm{g}$ of SARS-CoV-2-S-I53-50NPs (equal to $30 \mu \mathrm{g}$ of SARS-CoV-2-S) formulated 1:1 in Squalene Emulsion adjuvant (Polymun, Klosterneuburg, Austria). The rabbits were bled on the day of immunization and then at weeks 2 , 4 , 6 , and 14.

Female Balb/cAnNCrl mice received subcutaneous immunizations into the neck skin-fold at weeks 0,4 , and 12 . The immunization mixture contained $13 \mu \mathrm{g}$ of SARS-CoV-2-S-153-50NPs (equal to $10 \mu \mathrm{g}$ of SARS-CoV-2-S) adjuvanted with $50 \mu \mathrm{g}$ of polyinosinic-polycytidylic acid (Poly-IC; Invivogen). Blood was collected at weeks -1, 2, 6 and 14. Two out of eight mice were sacrificed at week 6 to allow interim analysis of the induced humoral response.

\section{Patient samples}

Patients with at least one nasopharyngeal swab positive for SARS-CoV-2 as determined by qRT-PCR (Roche LightCycler480, targeting the Envelope-gene 113bp) were included. Patients using immunosuppressive mediation (equivalent of $>7.5 \mathrm{mg}$ prednisolone) were excluded from the study. Included patients signed written informed consent forms. A venipuncture was performed to obtain blood in Acid Citrate Dextrose tubes for serum collection approximately four weeks after onset of COVID-19 symptoms (Brouwer et al., 2020).

\section{ELISAS}

Ni-NTA plates (QIAGEN) were loaded with $2 \mu \mathrm{g} / \mathrm{mL}$ of SARS-CoV-2 S protein in TBS for $2 \mathrm{~h}$ at RT. Next, washed plates were blocked for $1 \mathrm{~h}$ with TBS/2\% skimmed milk. Four-fold serial dilutions of inactivated sera, starting from a 1:200 dilution for mice and rabbit sera, and 1:100 dilution for macaque sera, were added in TBS/2\% skimmed milk/20\% sheep serum and incubated for $2 \mathrm{~h}$ at RT. Following plate washing, a 1:3000 dilution of secondary antibody in TBS/2\% skimmed milk was added for $1 \mathrm{~h}$ at RT. For mice, rabbit and macaque sera horseradish peroxidase (HRP)-labeled goat anti-mice lgG, HRP-labeled goat anti-rabbit lgG and HRP-labeled goat antihuman IgG (Jackson Immunoresearch) was used, respectively. Finally, after washing plates with TBS/0.05\% Tween-20, developing solution ( $1 \% 3,3^{\prime}, 5,5^{\prime}$-tetranethylbenzidine (Sigma-Aldrich), $0.01 \% \mathrm{H}_{2} \mathrm{O}_{2}, 100 \mathrm{mM}$ sodium acetate and $100 \mathrm{mM}$ citric acid) was added to each well and a colorimetric endpoint was obtained by adding $0.8 \mathrm{M} \mathrm{H}_{2} \mathrm{SO}_{4}$ after $1.5 \mathrm{~min}$. Binding endpoint titers were determined using a cutoff of $5 x$ background.

As affinity differences between species-specific secondary Abs may bias comparisons between endpoint titers of macaque and convalescent human sera, we used a different ELISA setup to compare S protein and RBD binding responses. Specifically, ELISA binding responses are compared to a standard curve of species-specific polyclonal IgG so that a semiquantitative measure of specific IgG concentrations can be obtained. High-binding plates were direct-coated overnight at $4{ }^{\circ} \mathrm{C}$ with $2 \mu \mathrm{g} / \mathrm{mL}$ of SARSCoV-2 S or $0.4 \mu \mathrm{g} / \mathrm{mL}$ of SARS-CoV-2 RBD in PBS. For capture of the standard curve (i.e., macaque and human polyclonal IgG), plates were coated with 1:2000 (for capture of polyclonal macaque lgG) or 1:1000 (for capture of polyclonal human lgG) of goat anti-Human IgG $\lambda$ and $\kappa$ (Southern Biotech). The next day, plates were washed with TBS than contained 0.05\% Tween-20 (TBST) and blocked for $1 \mathrm{~h}$ with Casein buffer (Thermo Fisher Scientific). A 1:100, 1:1000 and 1:10,000 dilution of macaque or human serum in Casein buffer were then added to the wells containing S protein or RBD. Five-fold serial dilutions of polyclonal macaque (Molecular Innovations) or human IgG, starting at a concentration of $1 \mu \mathrm{g} / \mathrm{mL}$, were added to wells containing the coated goat anti-Human IgG $\lambda$ and $\kappa$. Standards and samples were applied in duplicate. Following a $1 \mathrm{~h}$ incubation at RT, the plates were washed with TBST and secondary antibody diluted in Casein buffer was added for $1 \mathrm{~h}$. For the plates containing human sera and standard, a 1:3000 dilution of HRP-labeled goat anti-human IgG (Jackson Immunoresearch) was used. For plates containing macaque sera and standard, a 1:50,000 dilution of biotinylated mouse anti-monkey lgG was used (Southern Biotech), followed by a $1 \mathrm{~h}$ incubation with a 1:3000 dilution of HRP-labeled streptavidin (Biolegend) in Casein. Finally, after washing plates with TBST, developing solution (1\% 3,3',5,5'-tetranethylbenzidine (Sigma-Aldrich), $0.01 \% \mathrm{H}_{2} \mathrm{O}_{2}, 100 \mathrm{mM}$ sodium acetate and $100 \mathrm{mM}$ citric acid) was added to each well and a colorimetric endpoint was obtained by adding $0.8 \mathrm{M} \mathrm{H}_{2} \mathrm{SO}_{4}$ after $5 \mathrm{~min} . \mathrm{OD}_{450}$-values that fell within the linear range of the standard curve were fitted and the concentration of SARS-CoV-2 S protein and RBD-specific IgG was determined.

\section{Pseudovirus neutralization assay}

To generate SARS-CoV-2 pseudovirus, HEK293T cells (ATCC, CRL-11268) were transfected with a pHIV-1 ${ }_{\text {NL43 }} \Delta$ ENV-NanoLuc reporter virus plasmid and a SARS-CoV-2-S ${ }_{\Delta 19}$ plasmid (Schmidt et al., 2020). Cell supernatant containing the pseudoviruses was harvested $48 \mathrm{~h}$ post transfection, centrifuged for $5 \mathrm{~min}$ at $500 \mathrm{xg}$ and sterile filtered through a $0.22 \mu \mathrm{m}$ pore size PVDF syringe filter. For neutralization assays HEK293T expressing the SARS-CoV-2 receptor ACE2 (HEK293T/ACE2) were cultured in DMEM (GIBCO), supplemented with $10 \%$ FBS, penicillin $(100 \mathrm{U} / \mathrm{mL})$, and streptomycin $(100 \mu \mathrm{g} / \mathrm{mL})$.To determine the neutralization activity in serum, saliva or nasopharyngeal samples, HEK293T/ACE2 cells were first seeded in 96-well plates coated with $50 \mu \mathrm{g} / \mathrm{mL}$ poly-I-lysine at a density of $2 \times 10^{4}$ /well in the culture medium described above but with GlutaMax (GIBCO) added. The next day, duplicate serial dilutions of heat inactivated samples were prepared in the same medium as used for seeding of cells and mixed 1:1 with pseudovirus. This mixture was incubated at $37^{\circ} \mathrm{C}$ for $1 \mathrm{~h}$ before adding it to the HEK293T/ACE2 cells in a 1:1 ratio with the cell culture medium. After $48 \mathrm{~h}$, the cells were lysed and lysate was transferred into half area 96-well white microplates (Greiner bio-one). Luciferase activity was measured in the lysates using the Nano-Glo Luciferase Assay System (Promega) with a Glomax system (Turner BioSystems). Relative 
luminescence units (RLU) were normalized to those from cells infected with SARS-CoV-2 pseudovirus in the absence of sera/saliva/ swabs. Neutralization titers ( $\left(\mathrm{D}_{50}\right.$-values) were determined as the serum dilution at which infectivity was inhibited by $50 \%$.

\section{Authentic virus neutralization assay}

Serum samples were tested for their neutralization activity against SARS-CoV-2 (German isolate; GISAID ID EPI_ISL 406862; European Virus Archive Global \#026V-03883) as described previously (Okba et al., 2020). In short, serum samples were serially diluted in $50 \mu \mathrm{L}$ Opti-MEM I (GIBCO), supplemented with GlutaMAX (GIBCO) and penicillin (100 U/mL). Serum dilutions were mixed with 400 plaque-forming units of virus to a total of $100 \mu \mathrm{L}$. This mixture was incubated at $37^{\circ} \mathrm{C}$ for $1 \mathrm{~h}$. After incubation, the mixtures were put on Vero-E6 cells (ATCC CRL-1586) and incubated for $1 \mathrm{~h}$. Cells were then washed, Opti-MEM I supplemented with GlutaMAX (GIBCO) was added, and incubated for $8 \mathrm{~h}$. Cells were fixed with $4 \%$ formaldehyde in PBS and stained with polyclonal rabbit anti-SARS-CoV Ab (Sino Biological) and secondary Alexa488 conjugated goat-anti-rabbit Ab (Invitrogen). Plates were scanned on the Amersham Typhoon Biomolecular Imager (channel Cy2; resolution $10 \mu \mathrm{m}$; GE Healthcare). Data was analyzed using ImageQuant TL 8.2 image analysis software (GE Healthcare).

\section{Protein coupling to Luminex beads}

Proteins were covalently coupled to Magplex beads (Luminex Corporation) using a two-step carbodiimide reaction and a ratio of $75 \mu \mathrm{g}$ protein SARS-CoV-2 S protein to 12,5 million beads. Magplex beads (Luminex Corporation) were washed with $100 \mathrm{mM}$ monobasic sodium phosphate $\mathrm{pH} 6.2$, activated for $30 \mathrm{~min}$ on a rotor at RT by addition of Sulfo-N-Hydroxysulfosuccinimide (Thermo Fisher Scientific) and 1-Ethyl-3-(3-dimethylaminopropyl) carbodiimide (Thermo Fisher Scientific). The activated beads were washed three times with $50 \mathrm{mM}$ MES pH 5.0 and added to SARS-CoV-2 S protein which was diluted in $50 \mathrm{mM} \mathrm{MES} \mathrm{pH} \mathrm{5.0.} \mathrm{The} \mathrm{beads} \mathrm{and} \mathrm{protein}$ were incubated for $3 \mathrm{~h}$ on a rotator at RT. Afterward, the beads were washed with PBS and blocked with PBS containing $0.1 \%$ BSA, $0.02 \%$ Tween- 20 and $0.05 \%$ Sodium Azide at $\mathrm{pH} 7.0$ for 30 min on a rotator at RT. Finally, the beads were washed and stored in PBS containing $0.05 \%$ Sodium Azide at $4^{\circ} \mathrm{C}$ and used within 3 months.

\section{Luminex assays}

$50 \mu \mathrm{L}$ of a working bead mixture containing 20 beads per $\mu \mathrm{L}$ was incubated overnight at $4^{\circ} \mathrm{C}$ with $50 \mu \mathrm{L}$ of diluted serum, saliva or nasopharyngeal swab. Pilot experiments determined the optimal dilution for detection of SARS-CoV-2 S protein-specific IgG, IgA and IgM antibodies in serum to be 1:50,000, for the detection of antibody binding to Fc $\gamma$ RIla, Fc $\gamma$ RIIla and C1q in serum at 1:500 and for detection of S protein-specific IgG and IgA in saliva and nose fluid at 1:20. Plates were sealed and incubated on a plate shaker overnight at $4^{\circ} \mathrm{C}$. The next day, plates were washed with TBS containing $0.05 \%$ Tween-20 (TBST) using a hand-held magnetic separator. Beads were resuspended in $50 \mu \mathrm{L}$ of Goat-anti-human IgG-PE, Goat-anti human IgA-PE or Mouse-anti human IgM-PE (Southern Biotech) and incubated on a plate shaker at RT for $2 \mathrm{~h}$. For C1q binding, beads were resuspended in $50 \mu \mathrm{L}$ purified human C1q (Complement Technology, Inc.), which was biotinylated and conjugated to Streptavidin-PE. For the detection of Fc $\gamma$ RIla and Fc $\gamma$ RIIla binding, beads were resuspended in $50 \mu \mathrm{L}$ biotinylated human Fc $\gamma$ RIla and Fc $\gamma$ RIlla ectodomain dimers (courtesy of Bruce Wines and Mark Hogarth) for $2 \mathrm{~h}$ incubation, after which the beads were washed with TBST and then incubated with $50 \mu \mathrm{L}$ Streptavidin-PE (Invitrogen) on a plate shaker for $1 \mathrm{~h}$. Afterward, the beads were washed with TBST and resuspended in $110 \mu \mathrm{L}$ Bioplex sheath fluid (Bio-Rad). The beads were agitated for a few minutes on a plate shaker at RT and then readout was performed on the Bioplex 200 (Bio-Rad). Resulting mean fluorescence intensity (MFI) values were corrected by subtraction of MFI values from buffer and beads only wells. Relative MFI values were obtained by dividing the MFI by the background MFI at week 0 . Reproducibility of the results was confirmed by performing replicate runs.

SARS-CoV-2 S protein-specific CD4- and cTfh cell analysis using an activation induced marker (AIM) assay Cryopreserved macaque PBMCs from 2 weeks after final immunization (week 12) were thawed and counted. $1 \times 10^{6}$ cells per condition were plated in $96 \mathrm{U}$-shape well plates (CELLSTAR, Kremsmünster) and rested for 2-3 h in RPMI (GIBCO), supplemented with $10 \%$ FBS, $1 \mathrm{mM}$ HEPES (GIBCO), penicillin (100 U/mL), and streptomycin $(100 \mu \mathrm{g} / \mathrm{mL})$. Subsequently, cells were incubated with $0.5 \mathrm{mg} / \mathrm{mL}$ anti-CD40 (Miltenyi Biotec) for $15 \mathrm{~min}$ at $37^{\circ} \mathrm{C}$, to prevent downregulation of CD40 ligand (CD40L) by blocking CD40$\mathrm{CD} 40 \mathrm{~L}$ interaction. PBMCs were stimulated for $18 \mathrm{~h}$ at $37^{\circ} \mathrm{C}$ with $5 \mathrm{mg} / \mathrm{mL}$ SARS-CoV-2 S protein. As a negative control no stimulants were added, and as a positive control $1 \mathrm{mg} / \mathrm{mL}$ Staphylococcal enterotoxin B was used. Thereafter, PBMCs were washed using FACS buffer (PBS, supplemented with 1\% FBS). PBMCs were then incubated with the cTfh-specific chemokine receptor antibody CXCR5 PE-Cy7 (clone MU5UBEE; eBioscience) for $10 \mathrm{~min}$ at $37^{\circ} \mathrm{C}$. Next, the following antibodies and viability dye were incubated with PBMCs at RT for 20 min: anti-CD3 BUV395 (clone SP34-2; BD Biosciences), anti-CD4 BUV495 (clone SK3; BD Biosciences), anti-CD154 BV421 (clone TRAP1; BD Biosciences), anti-CD69 BV785 (clone FN50; BD Biosciences), anti-4-1BB APC (clone 4B41; Biolegend) and LiveDead-eF780 (eBioscience). Cells were washed twice with FACS buffer before acquisition on the BD LSR II Fortessa 5 lasers flow cytometer (BD biosciences). Analysis was performed on FlowJo v.10.7.1.

SARS-CoV-2 S protein and RBD-specific B cell analysis Biotinylated SARS-CoV-2 S protein and RBD were conjugated to streptavidin-bound fluorophores. Briefly, the biotinylated proteins were incubated for a minimum of $1 \mathrm{~h}$ at $4^{\circ} \mathrm{C}$ with the streptavidin-conjugates AF647 (Biolegend), BV421 (Biolegend) and BB515 (BD 
Please cite this article in press as: Brouwer et al., Two-component spike nanoparticle vaccine protects macaques from SARS-CoV-2 infection, Cell (2021), https://doi.org/10.1016/j.cell.2021.01.035
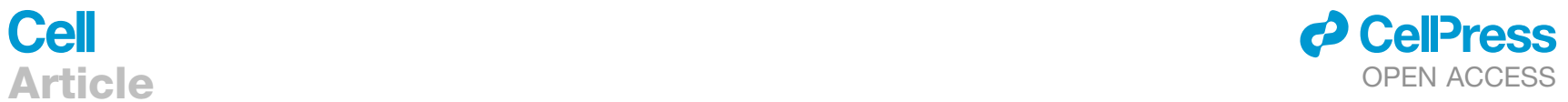

Biosciences) at a 1:2 protein to fluorochrome ratio. The fluorescent probes were incubated for at least $10 \mathrm{~min}$ with $10 \mathrm{mM}$ biotin (GeneCopoeia) to saturate the unconjugated streptavidin-fluorochrome complexes. Cryopreserved macaque PBMCs from 2 weeks after final immunization (week 12) were thawed and counted. $5 \times 10^{6}$ cells were stained for 30 min at $4^{\circ} \mathrm{C}$ with the fluorescent probes, a viability marker (LiveDead-eF780, eBiosciences) and the following B cell-specific antibodies: anti-CD20-PE-CF594 (clone 2H7; BD Biosciences), anti-IgG-PE-Cy7 (clone G18-145;BD Biosciences), anti-CD27-PE (clone M-T271; BD Biosciences), and antiIgM-BV605 (clone MHM-88; Biolegend). Cells were washed twice with FACS buffer and acquired on the FACS-ARIA-SORP 4 laser (BD Biosciences). Analysis was performed on FlowJo v.10.7.1.

\section{Viruses and cells}

For the cynomolgus macaque challenge study, SARS-CoV-2 virus (hCoV-19/France/ IDF0372/2020 strain; GISAID EpiCoV platform under accession number EPI_ISL_406596) was isolated by the National Reference Center for Respiratory Viruses (Institut Pasteur, Paris, France) (Lescure et al., 2020). Briefly, Vero E6 cells were cultured in DMEM + 5\% FBS. PCR-positive sample from patient 0371 was diluted 1:2 with DMEM with antibiotics but without FBS and supplemented with $1 \mathrm{ug} / \mathrm{ml}$ trypsin-TPCK (Sigma-Aldrich), added to the cells and incubated one hour at $37^{\circ} \mathrm{C}$. The inoculum was then replaced with DMEM medium containing antibiotics and $1 \mu \mathrm{g} / \mathrm{ml}$ trypsin-TPCK at $37^{\circ} \mathrm{C}$. Three days later, clear cytopathogenic effects were observed and RT-qPCR was performed to detect presence of virus. Culture supernatant was harvested, aliquoted and stored at $-80^{\circ} \mathrm{C}$.

Before the challenge experiment, virus stocks were first subjected to an additional passage on Vero E6 cells in DMEM (GIBCO) without FBS, supplemented with penicillin $(100 \mathrm{U} / \mathrm{mL})$, streptomycin $(100 \mu \mathrm{g} / \mathrm{mL})$, and $1 \mu \mathrm{g} / \mathrm{mL} \mathrm{TPCK}$-trypsin at $37^{\circ} \mathrm{C}$ in a humidified $\mathrm{CO} 2$ incubator. Virus was then titrated on Vero E6 cells by plaque reduction assay.

Virus quantification in cynomolgus macaque samples

Upper respiratory (nasopharyngeal and tracheal) and rectal specimens were collected with swabs (Viral Transport Medium, CDC, DSR-052-01). Tracheal swabs were performed by insertion of the swab above the tip of the epiglottis into the upper trachea at approximately $1.5 \mathrm{~cm}$ of the epiglottis. All specimens were stored between $2^{\circ} \mathrm{C}$ and $8^{\circ} \mathrm{C}$ until analysis by RT-qPCR with a plasmid standard concentration range containing an RdRp gene fragment including the RdRp-IP4 RT-PCR target sequence. SARS-CoV-2 E gene subgenomic mRNA (sgmRNA) levels were assessed by RT-qPCR using primers and probes previously described (Corman et al., 2020; Wölfel et al., 2020): leader-specific primer sgLeadSARSCoV2-F CGATCTCTTGTAGATCTGTTCTC, E-Sarbeco-R primer ATATTGCAGCAGTACGCACACA and E-Sarbeco probe HEX-ACACTAGCCATCCTTACTGCGCTTCG-BHQ1. The protocol describing the procedure for the detection of SARS-CoV-2 is available on the WHO website (https://www.who.int/docs/ default-source/coronaviruse/real-time-rt-pcr-assays-for-the-detection-of-sars-cov-2-institut-pasteur-paris.pdf?

sfvrsn=3662fcb6_2).

Chest computed tomography and image analysis

Acquisition was done using a computed tomography (CT) system (Vereos-Ingenuity, Philips). Animals were anesthetized and put in a supine position. Body temperature, oxygen saturation and heart rate were monitored. The collimation of the CT detector was $64 \times$ $0.6 \mathrm{~mm}$, with a $120 \mathrm{kV}$ tube voltage and around $120 \mathrm{~mA}$ intensity. The intensity was regulated by dose optimization tools (Dose Right, Z-DOM, 3D-DOM; Philips Healthcare). The reconstructed CT images had a slice thickness of $1.25 \mathrm{~mm}$, with an interval of $0.25 \mathrm{~mm}$. Lesions were defined, by internationally standard nomenclature, as ground glass opacity, crazy-paving pattern, consolidation or pleural thickening (Pan et al., 2020; Shi et al., 2020) (none, 0; GGO, 1; pleural thickening, 1; crazy-paving pattern, 3; consolidation, 3). Lesions and scoring were assessed in each lung lobe blindly and independently by two persons and final results were made by consensus. Overall CT scores include the lesion type, scored from 0 to 3 (None, 0; Slight, 1; Mild, 2; Severe, 3) and lesion volume, scored from 0 to 4 (None, $0 ;<25 \%$ of the lobe, $1 ; 25<x<50 \%$ of the lobe, $2 ; 50<x<75 \%$ of the lobe, $3 ; 75<x<100 \%$ of the lobe; 4 ) and summed for each lobe.

\section{ELISpot assays}

IFN $\gamma$ ELISpot assay of PBMCs was performed using the Monkey IFN $\gamma$ ELISpot PRO kit (Mabtech Monkey IFN $\gamma$ ELISPOT pro, \#3421M-2APT) according to the manufacturer's instructions. PBMCs were plated at a concentration of 200,000 cells per well and were stimulated with SARS-CoV-2 S protein at a final concentration of $5 \mu \mathrm{g} / \mathrm{mL}$. Plates were incubated for $42 \mathrm{~h}$ at $37^{\circ} \mathrm{C}$ in an atmosphere containing $5 \% \mathrm{CO}_{2}$, then washed 5 times with PBS and incubated for $2 \mathrm{~h}$ at $37^{\circ} \mathrm{C}$ with a biotinylated anti-IFN $\gamma$ antibody. After 5 washes, spots were developed by adding $0.45 \mu \mathrm{m}$-filtered ready-to-use BCIP/NBT-plus substrate solution and counted with an automated ELISpot reader ELRIFL04 (Autoimmun Diagnostika GmbH, Strassberg, Germany). Spot forming units (SFU) per $1.0 \times 10^{6}$ PBMCs are means of duplicates for each animal.

Viral sequencing

30 RNA samples from nasal swabs and bronchoalveolar lavage at day 3 and 5 were selected for sequencing. cDNA and multiplex PCR reactions were prepared following the ARTIC SARS-CoV-2 sequencing protocol v2 (Tyson et al., 2020). The inoculum was also sequenced. V3 primer scheme (https://github.com/artic-network/primer-schemes/tree/master/nCoV-2019/V3) was used to perform the multiplex PCR for SARS-CoV-2. All samples were run for 35 cycles in the two multiplex PCRs. Pooled and cleaned 


\section{$\infty$ Cell|Press} OPEN ACCESS

PCR reactions were quantified using QubitTM fluorometer (Invitrogen). The Ligation Sequencing kit (SQK-LSK109; Oxford Nanopore Technologies) was used to prepare the library following the manufacturer's protocol ("PCR tiling of COVID-19 virus," release F; Oxford Nanopore Technologies). 24 samples were multiplexed using Native Barcoding Expansion 1-12 and Native Barcoding Expansion 13-24 kits (EXP-NBD104 and EXP-NBD114; Oxford Nanopore Technologies). Two libraries of 24 samples were prepared independently and quantified by QubitTM fluorometer (Invitrogen). Quality control of two R9.4 flowcells (FLO-MIN106; Oxford Nanopore Technologies) was performed to assess pores viability. Next, 45 and 32 ng of library were respectively loaded as recommended by the manufacturer's protocol. Sequencing was performed on a GridION (Oxford Nanopore Technologies) for $72 \mathrm{~h}$ with high-accuracy Guppy basecalling (v3.2.10). After sequencing, demultiplexing was performed using Guppy v4.0.14 with the option-require_barcodes_both_ends to ensure high quality demultiplexing. Reads were then filtered by Nanoplot v1.28.1 based on length and quality to select high quality reads. Then, reads were aligned on the SARS-CoV-2 reference genome NC_045512.2 using minimap2 v2.17. Primary alignments were filtered based on reads length alignment and reads identity. Finally, variant calling was performed with Longshot v0.4.1. Identified variants were then analyzed using in-house scripts. Variants absent from the inoculum but present in one or more samples were selected for further analysis.

\section{QUANTIFICATION AND STATISTICAL ANALYSIS}

Details on the statistical analysis for the experiments can be found in the accompanying figure legends. Statistical significance between groups is indicated in the figures by stars: ${ }^{*}, p<0.05 ;{ }^{* \star}, p<0.01 ;{ }^{* \star \star}, p<0.001 ;{ }^{\star \star \star \star}, p<0.0001$. In addition, statistical significance between viral loads in the control and vaccinated groups are also indicated in the Results section by $p$ values. Medians are plotted for all experiments and comparisons between two groups were made using a Mann-Whitney U test (Excel 2016, GraphPad Prism 8.0/7.0). For mouse experiments 8 animals were used up to week 6, when 2 animals were euthanized for preliminary assessment of $(\mathrm{N}) \mathrm{Ab}$ titers. Due to low sample volumes the eight mouse samples at week -1 were randomly paired and pooled into 4 samples. The rabbit experiments were performed using 5 animals. In the macaque experiments, 6 animals were used in the vaccinated group and 4 animals were used in the control group. 


\section{Supplementall Figures}

A

\begin{tabular}{|c|c|c|c|c|c|c|c|c|c|c|c|c|c|c|c|c|c|c|c|c|}
\hline & $\bar{\Sigma} \overline{\underline{c}}$ & $\frac{N}{z}$ & $\frac{\text { N }}{z}$ & $\frac{g}{\dot{g}}$ & $\frac{0}{\tilde{z}}$ & స్ & 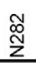 & 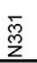 & 管 & 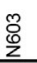 & $\frac{6}{\frac{0}{0}}$ & $\begin{array}{l}\sqrt{0} \\
\underline{0}\end{array}$ & $\begin{array}{l}\frac{2}{2} \\
\text { z }\end{array}$ & $\stackrel{\kappa}{\Sigma}$ & $\begin{array}{l}\bar{\infty} \\
z\end{array}$ & $\begin{array}{l}\frac{1}{2} \\
\frac{0}{2}\end{array}$ & $\begin{array}{l}\infty \\
\frac{0}{0} \\
\frac{0}{z}\end{array}$ & $\frac{\text { J }}{\sum}$ & Total & \\
\hline Mannose & 076 & $\overline{0}$ & 4 & 0 & 2 & 44 & $\overline{0}$ & 3 & 3 & 0 & 2 & 0 & $\overline{0}$ & 29 & 28 & $\overline{0}$ & 9 & $\overline{0}$ & Mannose & $\overline{11}$ \\
\hline Hybrid & 3 & 0 & 0 & 0 & 0 & 18 & 30 & 0 & 0 & 0 & 0 & 0 & 0 & 10 & 0 & 3 & 1 & 0 & Hybrid & 3 \\
\hline Complex & 10022 & 100 & 96 & 100 & 98 & 38 & 70 & 97 & 97 & 100 & 98 & 1001 & 100 & 61 & 72 & 82 & 90 & 100 & Complex & 85 \\
\hline Unoccupied & 00 & 0 & 0 & 0 & 0 & 0 & 0 & 0 & 0 & 0 & 0 & 0 & 0 & 0 & 0 & 15 & 0 & 0 & Unoccupied & 1 \\
\hline Fucosylation & $98 \quad 18$ & 37 & 76 & 97 & 97 & 18 & 25 & 97 & 97 & 100 & 98 & 1001 & 100 & 56 & 61 & 83 & 36 & 100 & Fucosylation & 73 \\
\hline Sialylation & 10 & 23 & 13 & 0 & 14 & 0 & 13 & 12 & 5 & 8 & 5 & 7 & 9 & 5 & 3 & 11 & 12 & 7 & Sialylation & 8 \\
\hline
\end{tabular}

B

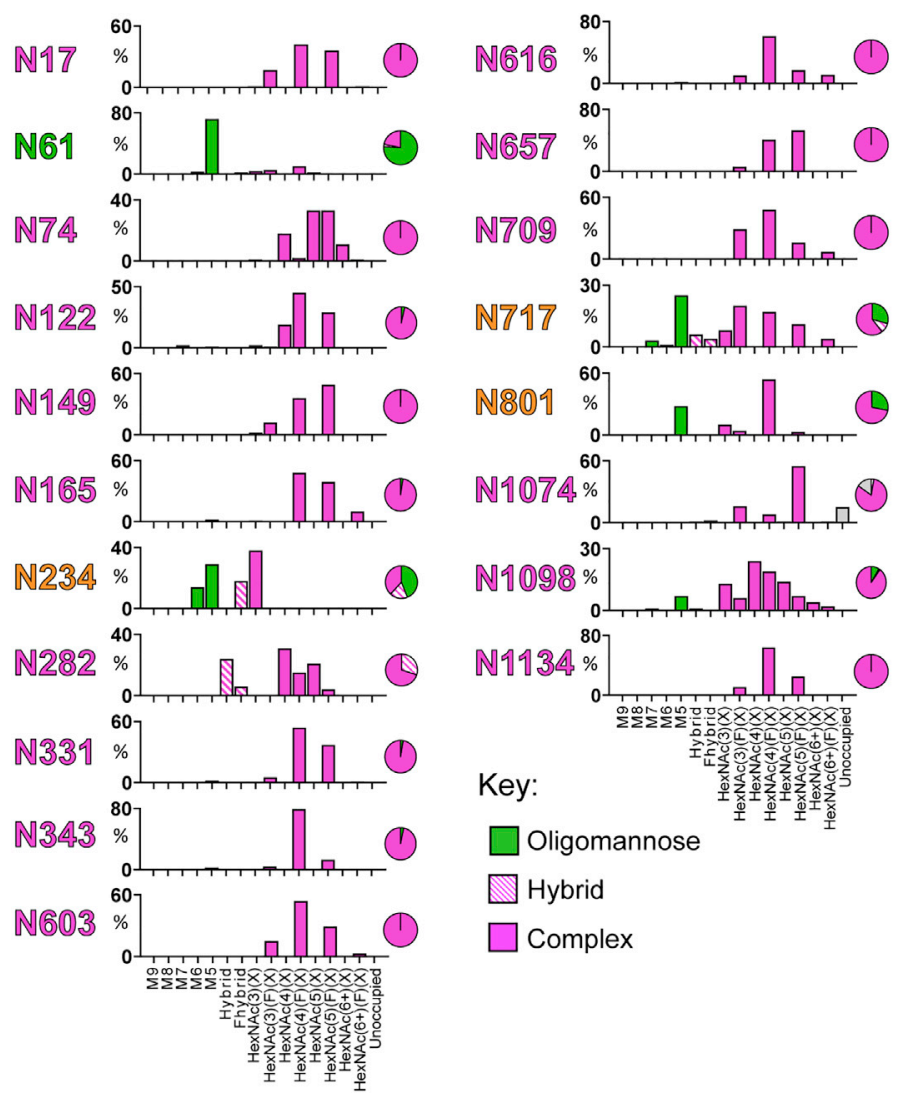

Figure S1. Site-specific glycan analysis of SARS-CoV-2 S I53-50NPs, related to Figure 1

(A) The table categorizes the glycan compositions into oligomannose-, hybrid-, and complex-type as well as the percentage of glycan species containing at least one fucose or one sialic acid residue. The overall averages are shown in the right-hand table. (B) Site-specific distribution of N-linked glycans. The graphs summarize quantitative mass spectrometric analysis of the glycan population present at individual $\mathrm{N}$-linked glycosylation sites simplified into categories of glycans. The oligomannose-type glycan series ( $M 9$ to $M 5 ; \mathrm{Man}_{9} \mathrm{GlcNAc}_{2}$ to $\mathrm{Man}_{5} \mathrm{GlcNAc}_{2}$ ) is colored green, afucosylated and fucosylated hybrid-type glycans (Hybrid \& F Hybrid) dashed pink, and complex glycans grouped according to the number of antennae and presence of core fucosylation (HexNAc(3)(X) to $\operatorname{HexNAc}(6+)(\mathrm{F})(\mathrm{X}))$ and are colored pink. Unoccupancy of an $\mathrm{N}$-linked glycan site is represented in gray. The pie charts summarize the quantification of these glycans. Glycan sites are colored according to oligomannose-type glycan content with the glycan sites labeled in green ( $80 \%-100 \%$ oligomannose), orange (30\%-79\% oligomannose) and pink ( $0 \%-29 \%$ oligomannose). 
A
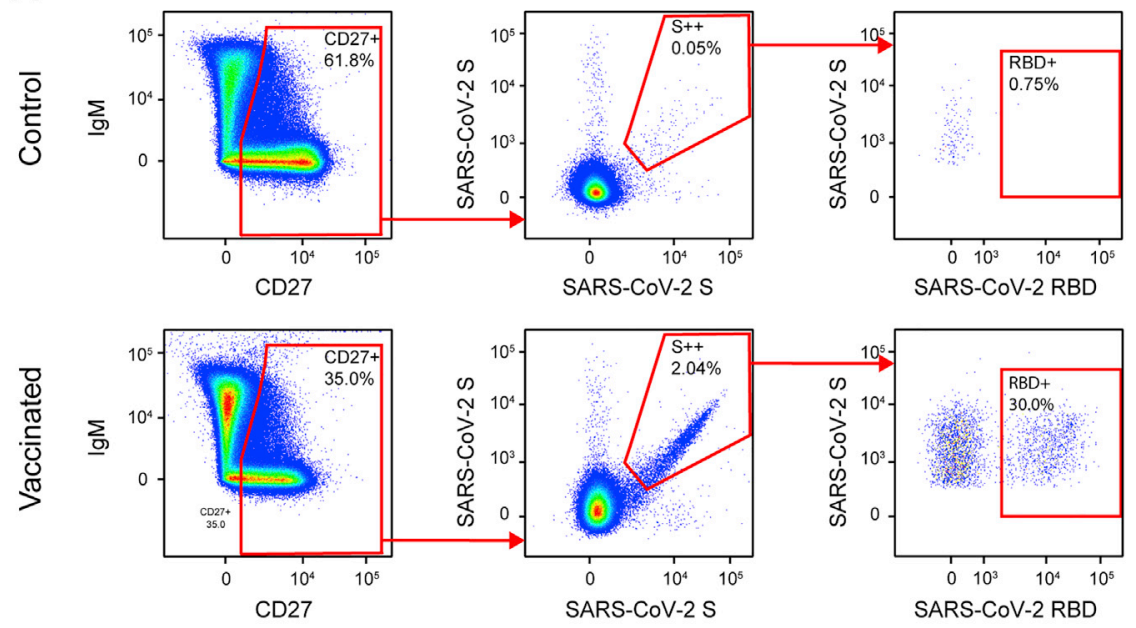

B

C
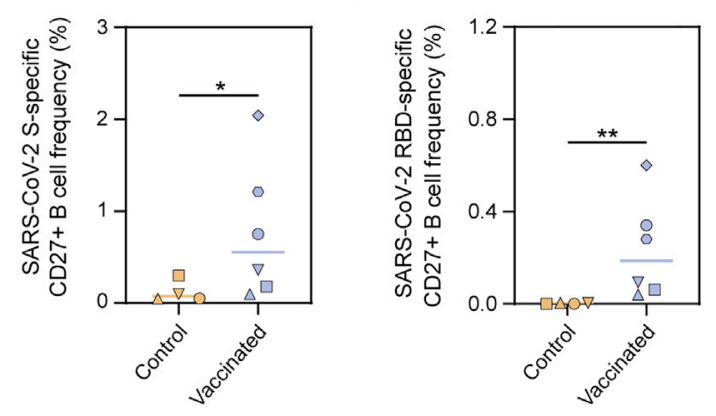

Figure S2. SARS-CoV-2 S-protein-specific CD27 ${ }^{+}$B cell responses in control and vaccinated macaques, related to Figure 4

(A) Representative gating strategy for the identification of SARS-CoV-2 S protein and RBD-specific CD27+ B cells for control (top) and vaccinated (bottom) macaques. The live $B$ cell population was selected and doublets were excluded (not shown). (B) Frequency of SARS-CoV-2 S protein-specific cells among CD27+ $B$ cells in control and vaccinated macaques. (C) Frequency of SARS-CoV-2 RBD-specific cells among CD27+ B cells in control and vaccinated macaques. In (B) and $(C)$ bars indicate median. Groups were compared using the Mann-Whitney $U$ test $\left({ }^{*} p<0.05 ;{ }^{* \star} p<0.01\right)$. 
A
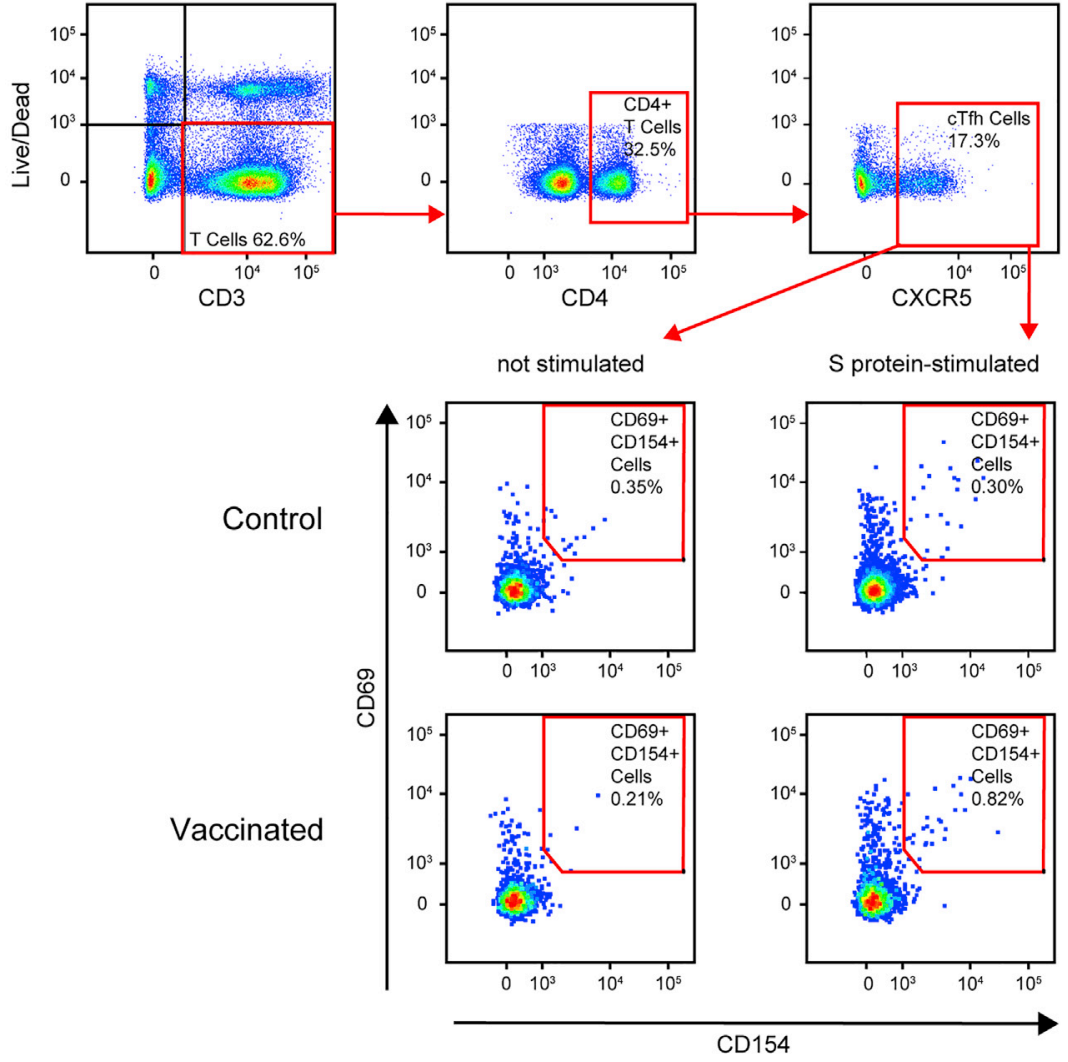

B

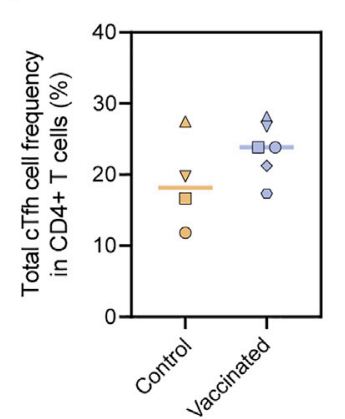

D

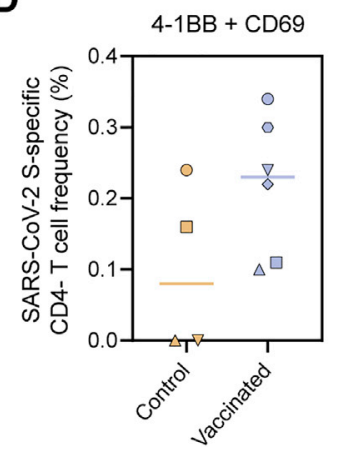

C

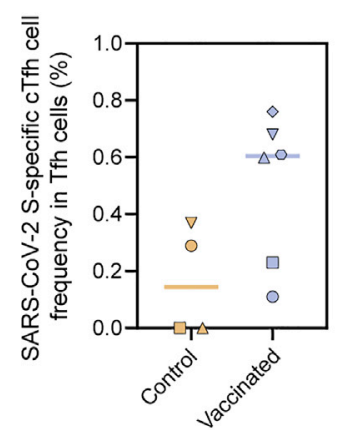

4-1BB + CD154

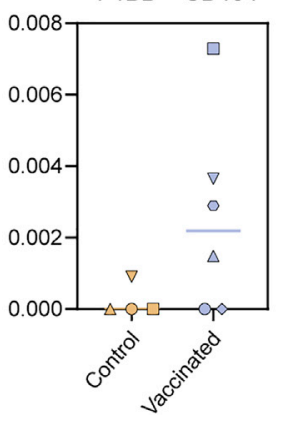


Figure S3. SARS-CoV-2 S-protein-specific Tfh cell and CD4- T cell responses in control and vaccinated macaques, related to Figure 4 (A) Representative gating strategy for the identification of SARS-CoV-2 S protein-specific Tfh cells. PBMCs were stimulated overnight with SARS-CoV-2 S protein and Tfh activation was assessed the next day by analyzing CD69 and CD154 expression. (B) Frequency of total Tfh cells in CD4+ T cell population following stimulation with SARS-CoV-2 S protein. (C) Frequency of SARS-CoV-2 S-protein specific Tfh cells within the total Tfh cell population. Corresponding background (i.e., frequency of activated Tfh cells in non-stimulated cells) has been subtracted from each data point. (D) Frequency of SARS-CoV-2 S protein-specific cells among CD4- T cells (CD8+ T cells by inference) as determined by the AIM assay using 4-1BB + CD69 (left) and 4-1BB + CD154 (right) as activation markers. Similar to (A), CD4- cells were stimulated overnight with SARS-CoV-2 S protein and activation was assessed using activation markers. Corresponding background (i.e., frequency of activated CD4- cells in non-stimulated cells) has been subtracted from each data point. In (B)-(D) bars indicate median. 
A

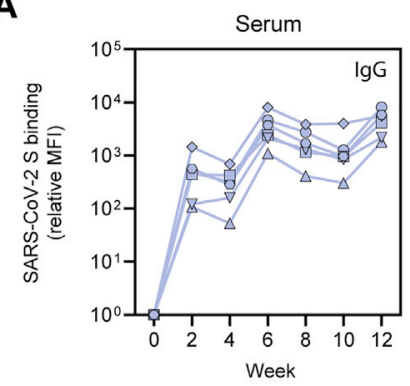

B

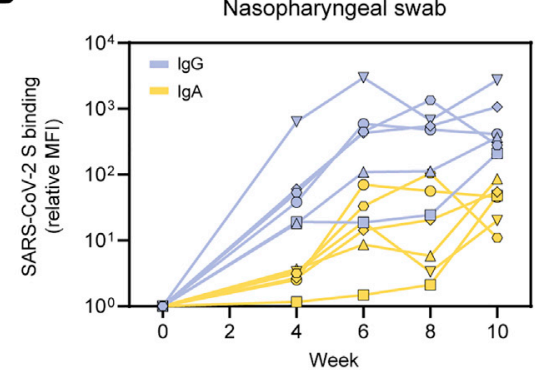

Serum

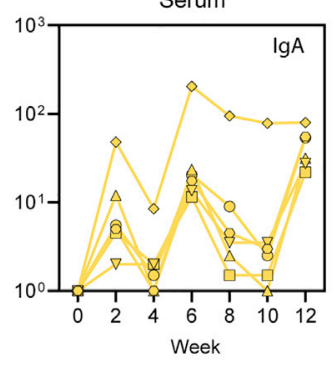

Serum

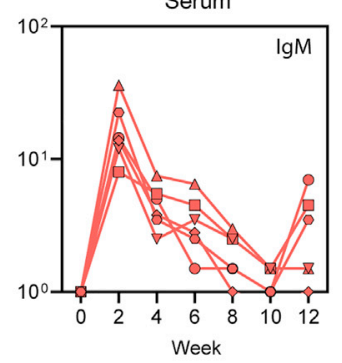

C

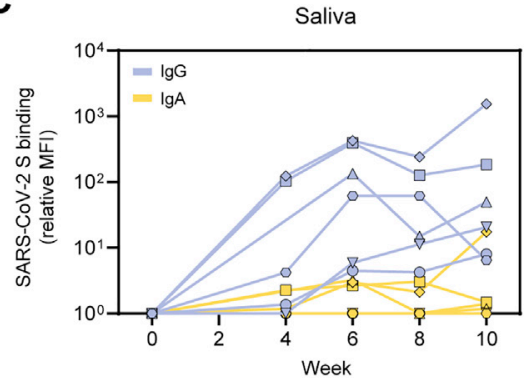

D
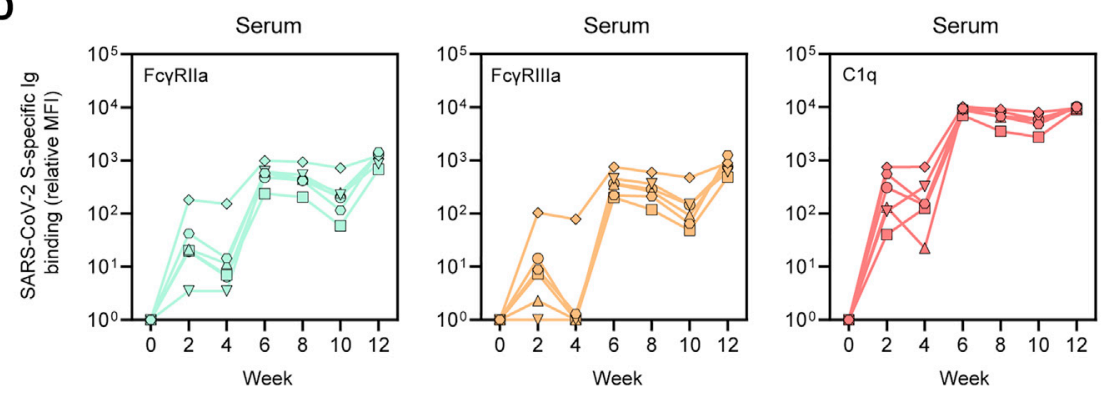

Figure S4. SARS-CoV-2 S-protein-specific Ig levels and Fc-receptor binding in vaccinated cynomolgus macaques in samples from diverse anatomical sites, related to Figure 5

(A) Relative MFI of IgG (left), IgA (middle) and IgM (right) binding to SARS-CoV-2 S protein measured with a Luminex-based serology assay in serum samples. (B) Relative MFI of IgG and IgA binding to SARS-CoV-2 S in nasopharyngeal swabs. (C) Relative MFI of IgG and IgA binding to SARS-CoV-2 S in saliva. (D) Relative

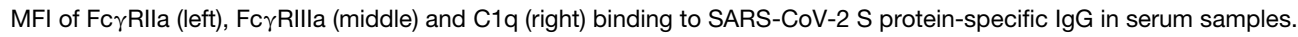


A
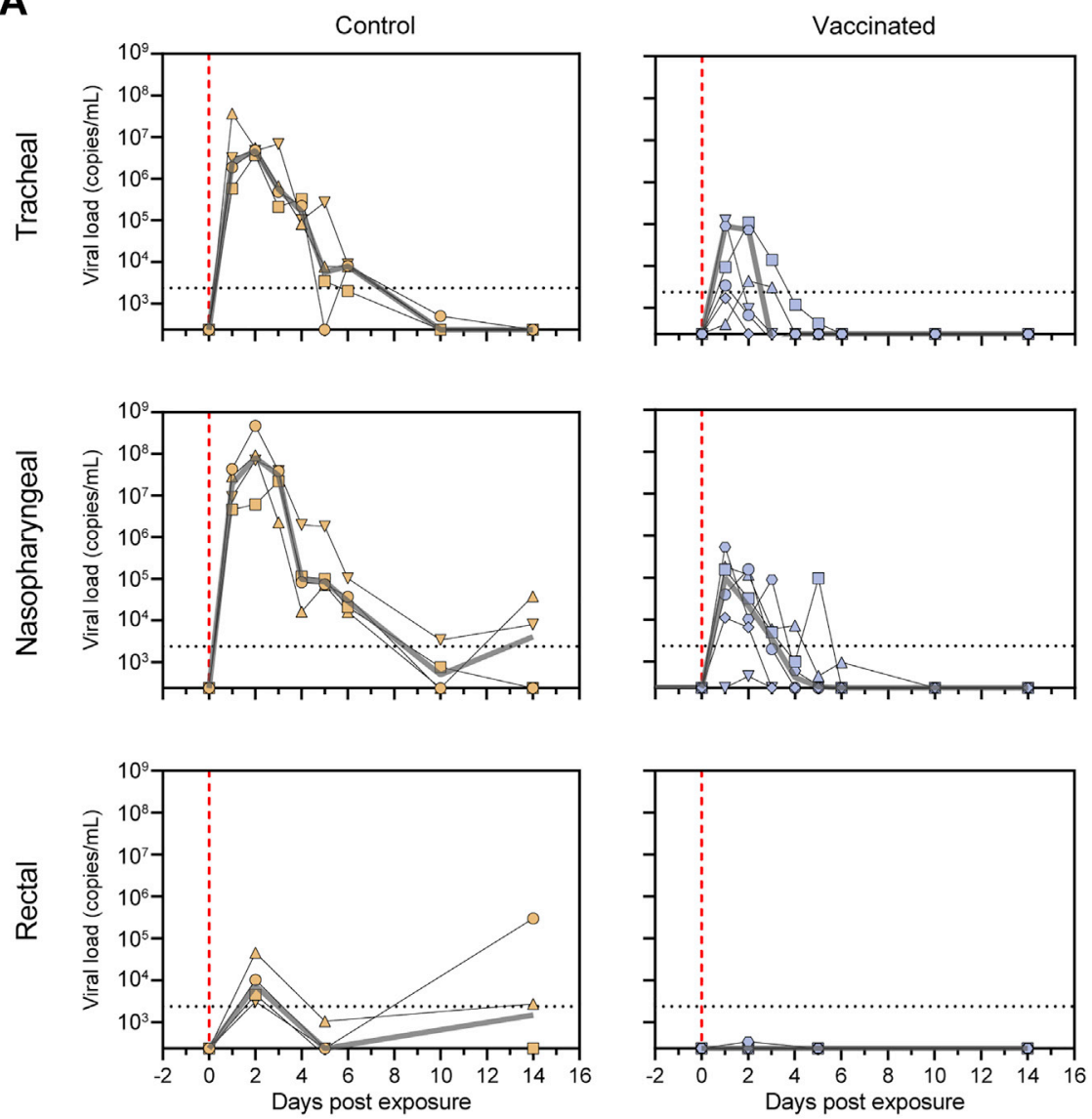

$\square$ MF2 $\rightarrow$ MF4 $\neg$ MF6

$\triangle$ MF7 $\diamond$ MF9 - Median

MF8 - MF10

B

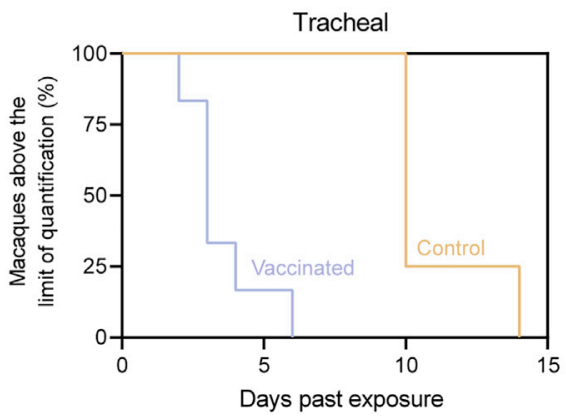

Figure S5. Viral loads in control and vaccinated cynomolgus macaques after SARS-CoV-2 challenge, related to Figure 6 (A) RNA viral loads in tracheal swabs (top), nasopharyngeal swabs (middle) and rectal samples (bottom) of control (left) and SARS-CoV-2 S-153-50NP vaccinated macaques (right) after challenge. The gray line represents the median viral load. Vertical red dotted lines indicate the day of challenge. Horizontal dotted lines indicate the limit of quantification. Symbols identify individual macaques. (B) Percentage of macaques in which the RNA viral loads is above the limit of quantification over time in tracheal swabs (left) and nasopharyngeal swabs (right). 
A
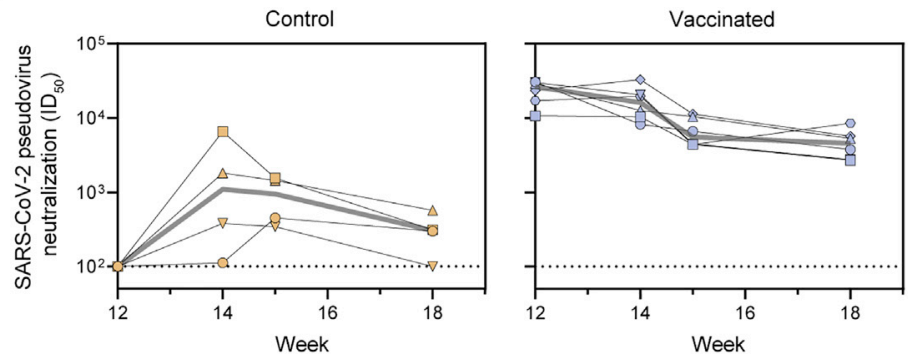

B
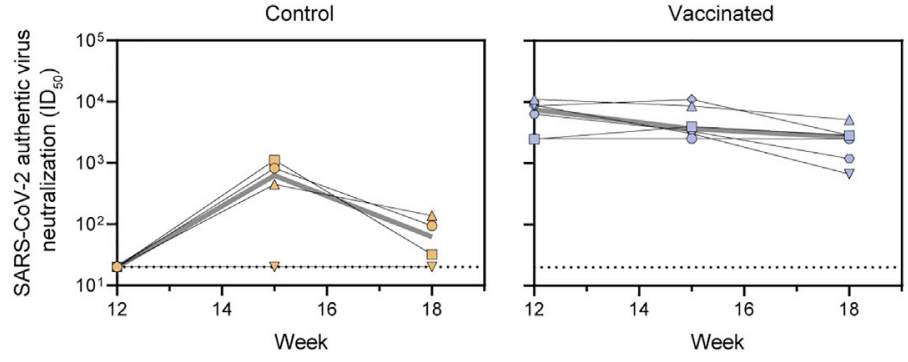

C
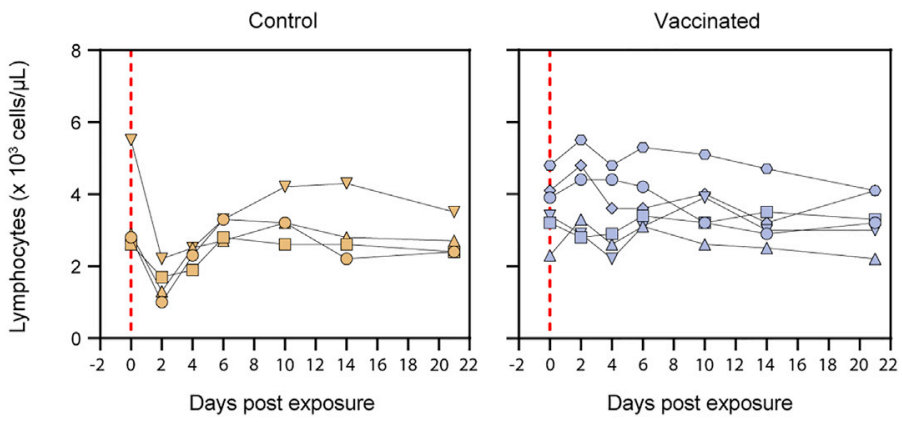

D
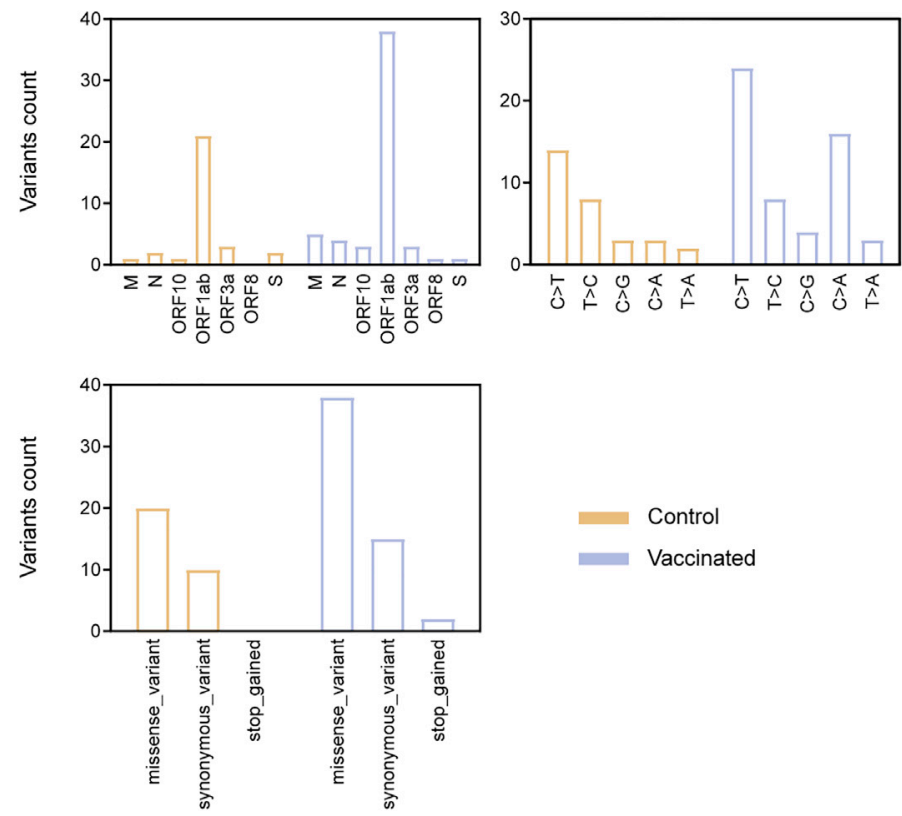

Control
Vaccinated 
Figure S6. Anamnestic immune response, lymphocyte counts, and emerged viral sequence variants in control and vaccinated cynomolgus macaques after SARS-CoV-2 challenge, related to Figure 6

(A) SARS-CoV-2 pseudovirus neutralization titers. The gray line represents the median titers over-time. (B) SARS-CoV-2 authentic virus neutralization titers. The gray line represents the median titers over-time. (C) Lymphocyte counts over time in the blood of control and SARS-CoV-2 S-I53-50NP vaccinated macaques after challenge. Vertical red dotted lines indicate the day of challenge. In (A)-(C) Symbols identify individual macaques as indicated Figure S5A. (D) Sum of viral variants found by viral sequencing, in nasopharyngeal swabs at $3 \mathrm{dpe}$ and $5 \mathrm{dpe}$, and in BAL at $3 \mathrm{dpe}$, specified for the ORF in which it was found (top left) the type of nucleotide change (top right) and the effect is has on the amino acid sequence (bottom; missense_variant = amino acid change, synonymous_variant = no amino acid change, stop_gained = introduction of a stop codon). For a list of all identified variants see Table S3. 